\title{
El STATUS QUO DE LA TECNOLOGÍA METALÚRGICA EN LA COSTA CENTRAL Y NORTE DEL PERÚ DURANTE EL PERIODO INTERMEDIO TARDÍO
}

\author{
Luisa Vetter Parodi*
}

\section{Resumen}

Los estudios sobre la tecnología metalúrgica precolombina de la costa norte han aumentado de manera considerable en los últimos años. Sin embargo, en la costa central el tema aún no despierta el interés de los investigadores. Lo poco que se conoce sobre la metalurgia de esta área revela que no tuvo un desarrollo tan avanzado como su par norteño, sobre todo en el periodo Intermedio Tardío, cuando las culturas norteñas llegaron a utilizar todas las técnicas orfebres, todos los metales y la mayoría de aleaciones conocidas en la época.

\section{Palabras clave}

Orfebrería, costa central, costa norte, Intermedio Tardío.

\begin{abstract}
Studies made on Pre-Colombian metallurgy technology from the Northern Coast have notably increased in recent years. Nevertheless, in the Central Coast the issue has not yet aroused the interest of researchers. The little knowledge gathered on metallurgy from this area reveals that development was not as advanced as in its northern pair, especially in the Late Intermediate Period, when northern cultures became users of all goldsmiths techniques, all metals and most alloys known at the time.
\end{abstract}

Keywords

Goldsmith, Central Coast, Northern Coast, Late Intermediate Period.

\footnotetext{
* Museo Nacional Sicán.
}

Correo electrónico: luchivetter@hotmail.com 


\section{INTRODUCCIÓN}

Los inicios de la metalurgia del antiguo Perú están fechados 4000 años atrás (Aldenderfer et al. 2008). Ya en el Horizonte Temprano este arte había alcanzado un gran desarrollo en la sierra norte, como lo demuestran los objetos encontrados en las tumbas excavadas en Kuntur Wasi, Cajamarca, por Julio C. Tello entre 1946 y 1947 y la Misión Japonesa (Onuki 1997; Seki 1997; Onuki y Inokuchi 2011). Sin embargo, en el periodo Intermedio Temprano, el desarrollo metalúrgico adquirió mayor fuerza en la costa y se prolongó en los periodos posteriores. Desde el siglo XIX, muchos viajeros como Baessler (1906), Squier (1974), Wiener (1983), entre otros, además de estudiosos como Uhle (Shimada 1991) y Reiss y Stübel (1998) han descrito las maravillosas piezas de metal que encontraron a lo largo de su recorrido por el Perú o que excavaron, como el caso de Reiss y Stübel, y Uhle. La mayoría de estas piezas fueron llevadas a Europa para ocupar las vitrinas de los museos interesados en el arte de los primeros orfebres sudamericanos.

Las culturas costeñas destacan por un desarrollo muy avanzado en las técnicas metalúrgicas, que se evidencia desde la aparición en la costa norte de un disco de cobre laminado y posiblemente dorado, hallado como ofrenda funeraria en el sitio de Puémape, en San Pedro de Lloc, fechado entre 1500 y 1300 a.C. (Elera y Pinilla 1990), mientras que en la costa central se excavaron varias piezas de oro con cobre martillado en el sitio de Mina Perdida, en el valle de Lurín, fechadas entre 1500 y 1100 a.C. (Burger y Gordon 1998).

Aunque se conocen estas evidencias tempranas de piezas de metal en la costa central, por alguna razón aún desconocida, la costa norte desarrolló ampliamente el arte de la fabricación de objetos de metal a través de nuevas técnicas y aleaciones, mientras que la otra región limitó su desarrollo a unas pocas técnicas y tipo de objetos (Carcedo et al. 2004).

En estas líneas revisaremos las distintas técnicas orfebres desarrolladas en ambas zonas costeñas durante el Intermedio Tardío, además compararemos las diversas formas de las piezas de metal, ya sean de uso utilitario o suntuario.

La producción metalúrgica de la costa norte ha sido intensamente estudiada por lo que se pondrá énfasis en las evidencias de la costa central, centrando la atención en dos casos en los que se recuperaron piezas de metal. Uno de ellos es una excavación reciente que formó parte de trabajos de arqueología de contrato y que está en pleno proceso de investigación (Proyecto de Rescate Arqueológico Loop Costa); y el otro caso corresponde a las excavaciones del Seminario de Arqueología del Instituto RivaAgüero de la Pontificia Universidad Católica del Perú en las décadas de 1960-1970 y que han sido poco difundidas (Cárdenas 1975).

\section{MARCO HISTÓRICO}

El periodo Intermedio Tardío empieza alrededor de 1000 d.C., luego del colapso de las grandes sociedades hegemónicas del Horizonte Medio, es decir de Wari y Tiahuanaco. En la costa, las sociedades locales se revitalizaron y alcanzaron una nueva identidad evidenciada en su cultura material, la que afirma su carácter regional y desarrollo independiente.

\section{El periodo Intermedio Tardío en la costa norte}

Al presentar los resultados de sus investigaciones en Pampa Grande, Shimada (1994) ofrece una posible explicación de lo que ocurrió en esta ciudad del periodo Moche Tardío durante el tránsito del Horizonte Medio al Intermedio Tardío. Los Mochicas del Norte gozaban de bienestar económico y político por el acceso a aguas de riego, el pastoreo de camélidos, la explotación del guano de las islas del litoral (que incluía el control de las mismas) y el acceso a los recursos marinos. Por otro lado, estas islas fueron consideradas lugares sagrados, lo cual era esencial para la cosmovisión moche. La situación de bienestar fue perturbada en el año 562 d.C., cuando se inició una sequía que duró treinta y dos años y que ocasionó una gran disminución en el volumen del agua, con terribles consecuencias para la economía y 
agricultura. Es por esta razón que la población se trasladó a Pampa Grande, en Lambayeque, a 50 $\mathrm{km}$ del litoral, construyendo un sitio estratégicamente ubicado en las tomas de agua de las partes altas del piedemonte, desde donde se controla el acceso a ellas.

Shimada (1994) afirma que para la construcción de la Huaca Fortaleza -que representaba la autoridad política y religiosa mochica en Pampa Grande- se requirió de una gran fuerza de trabajo y un gran número de artesanos de apoyo y servicio que necesitaban permanecer en el sitio. Este traslado de fuerza laboral y de artesanos requirió de nuevas normas y medidas coercitivas para crear el Estado, así las instituciones religiosas mochicas proporcionaron el marco institucional para establecer la nueva capital, pero en ese proceso el Estado mochica se transformó de un Estado religioso a uno laico naciente, con los consiguientes problemas que implica tratar de gobernar a grupos de orígenes diversos. Por tanto, Shimada sostiene que la causa del descontento de las masas que precondicionó el colapso de esta entidad política se halla desde el inicio de la formación del Estado.

El surgimiento del Estado Moche Tardío y su capital fue un proceso de adaptación a condiciones de estrés, una solución racional a necesidades percibidas, sin embargo, cuando se terminó la construcción de la Huaca Fortaleza y se mejoró la provisión de agua, su mantenimiento resultó progresivamente costoso para las masas. Shimada (1994: 261) cuestiona la posibilidad de que el liderazgo de Moche Tardío -en cuanto a su transformación de sagrado a secular- haya conseguido una estabilidad de larga duración en la ciudad, pues alrededor de fines del siglo séptimo, la sociedad Moche Tardío de Pampa Grande colapsó por problemas internos o alguna amenaza externa. El colapso de la ciudad y del Estado fue probablemente rápido y violento, como lo atestiguan las huellas de los incendios intencionales en la arquitectura ceremonial. Para Shimada (1994: 261) las evidencias disponibles indican que la causa inmediata del colapso fue una revuelta interna, aunque las amenazas de los grupos foráneos (waris y cajamarcas) también pueden haber contribuido.
Luego del colapso de Pampa Grande, no hay evidencias concretas sobre la formación de Sicán Temprano o Lambayeque. Sin embargo, alrededor de 900 d.C., a comienzos del periodo Intermedio Tardío, la cultura Sicán o Lambayeque -herederos de los Mochica del Nortealcanzó su auge en la zona de Batán Grande, en Lambayeque, cuya iconografía muestra el sincretismo entre Moche y Wari, reflejado en el personaje representado en la cerámica y los objetos de metal con los ojos alados y en ocasiones con el típico sombrero de cuatro puntas característico de Wari. Precisamente alrededor de 900 d.C. tuvo lugar una innovación tecnológica importante: comenzó la producción en masa de cobre arsenical, y por lo tanto fue el inicio de la Edad de Bronce en los Andes (Hocquenghem 2004, 2010).

Los herederos de los Mochica del Sur, es decir los chimú, se desarrollaron un poco más tarde, ca. 1200 d.C. en el valle de Moche. Según Shimada (1994), la cerámica de la cultura Chimú se caracteriza por formas y motivos de sus antecesores: los cupisnique, mochica, wari e incluso sicán.

\section{El periodo Intermedio Tardío en la costa central}

La costa central abarca los valles desde Huaura por el norte hasta Cañete por el sur ( $c f$. Lumbreras 1974, citado por Eeckhout 2004a), aunque algunos investigadores restringen este nombre para el conjunto de valles bajos de las cuencas de los ríos Chillón, Rímac y Lurín, los cuales conformaron en épocas precolombinas una unidad agropecuaria e hidráulica (Rostworowski 1978; Eeckhout 2000; Villacorta 2004, entre otros).

Los estudios realizados para el entendimiento del periodo Intermedio Tardío en la costa central se han referido generalmente a los estilos cerámicos (p.e. Falconí 2008; Dolorier y Casas 2008; Feltham e Eeckhout 2004) y los cambios arquitectónicos, sobre todo en el caso de la arquitectura monumental de Pachacámac (p.e. Eeckhout 2004b; Villacorta 2004). 
En su estudio introductorio a los trabajos de Uhle en Pachacámac, Shimada (1991: XXXIX) hace una revisión de los cambios, principalmente arquitectónicos, que ocurrieron en este santuario en los diferentes periodos cronológicos. Así señala que luego del colapso del imperio Wari y el abandono de Cajamarquilla, el periodo Intermedio Tardío corresponde al resurgimiento de Pachacámac, acompañado por una intensa actividad de construcción en las casas-castillo o aterrazados, como Uhle denominó a las construcciones más importantes en número y prominencia construidas en Pachacámac durante este periodo y a lo largo de dos calles mayores que se cruzan (norte-sur y este-oeste). Basándose en las complejas divisiones internas ubicadas dentro de las murallas de gran tamaño y con acceso limitado, Uhle (citado por Shimada 1991) las consideró como los palacios de los jefes, pero ahora son conocidas como pirámides con rampa. Shimada (1991: XL) las define como grandes montículos aterrazados, de varios niveles y con rampas centrales y cortas, que unen un nivel con el siguiente. Esta configuración básica se repite con diferentes escalas en las quince pirámides con rampa identificadas en la porción central del lugar.

Shimada(1991) consideraqueestasestructuras y el sector central del sitio fueron ocupados de forma continua desde el Horizonte Medio hasta la conquista europea. Además menciona que en la costa norte hay plataformas monumentales de varios niveles que son atribuibles a la cultura Sicán Medio (900-1100 d.C.), por ejemplo las Huacas Miguelito y Teodora en el valle de Zaña, las Huacas Chornancap y Taco o Éten en el valle bajo de Lambayeque y las Huacas El Corte, Rodillona y El Moscón en Batán Grande. Esas plataformas no tenían murallas que las encerraran y fueron construidas por capas sobrepuestas y llenadas y selladas con cámaras de adobe, al igual que las pirámides con rampa de Pachacámac. Tomando en cuenta varias líneas de evidencia que indican que en el Horizonte Medio Época 3, Pachacámac estuvo bajo fuerte influencia de Sicán Medio, las pirámides con rampa dentro de los espacios con murallas pueden ser vistas como una síntesis del Horizonte Medio Tardío de las costas norte y central.
Shimada (1991) señala también que la interpretación de la función de las pirámides con rampa habría estado muy influenciada por datos históricos que se refieren a un tiempo relativamente pacífico antes de la llegada de los incas a la costa central y el control del sitio de Pachacámac por el Señorío de Ichimay local. Pachacámac fue el más influyente centro ceremonial de la costa central y recibió trabajo, tributos y un amplio rango de bienes materiales de las comunidades agrícolas de la costa central, de las alturas adyacentes y de territorios más alejados aún.

Por su parte, Jiménez Borja y Bueno (1970: 16, citados por Shimada 1991: XLII) argumentan que las pirámides con rampa fueron edificios provinciales y familiares: las estructuras cívicas y ceremoniales, las etnias políticas y los señores que rendían culto a Pachacámac tenían la obligación de servir con trabajos y bienes materiales. El diseño arquitectónico de los edificios provinciales permitía el control del movimiento físico e incrementaba la importancia de realizar el largo ascenso a la cima de la pirámide. Jiménez Borja veía este ascenso como una alegoría de la transición de la vida mortal terrestre a una celestial y mítica (1985: 42, citado por Shimada 1991). Por otro lado, las distintas orientaciones de las pirámides y sus rampas apuntaban a los lugares de origen de estos grupos provinciales (p. e. los valles del Rímac, Chillón, Chancay, y Cieneguilla y Huarochirí en el medio y la cabecera del valle de Lurín respectivamente). Sin embargo, la presencia de textiles y cerámica de varios estilos coexistentes en el Intermedio Tardío de la costa central no ha sido suficientemente explicada.

Por su parte, Eeckhout (2004b) y otros autores señalan que las interpretaciones etnohistóricas limitaron el entendimiento del sitio de Pachacámac y sus edificios, que deben ser estudiados con métodos arqueológicos.

Shimada (1991: XLIII) refiere que la unidad que caracteriza a las quince pirámides con rampa implica que el Señorío de Ichimay y el culto a Pachacámac tuvieron considerable fuerza política y/o ideológica. Así se habría formado una confederación y jerarquía sociopolítica 
que mantenían el culto y el centro ceremonial de Pachacámac. Las redes sociales y económicas así formadas habrían promovido el comercio interétnico, sirviendo el santuario como un puerto de trueque. El prestigio, así como los cimientos sociales y económicos del culto de Pachacámac, habrían sido fortalecidos de esta forma.

El estudio de los materiales recuperados en los contextos funerarios constituye otra forma de entender el proceso cultural de la costa central. Guerrero (2004:157-174) analizó la cerámica de los contextos funerarios que excavó en varios lugares del valle del Rímac como Rinconada y Armatambo, y también aquellos recuperados durante las excavaciones de Jiménez Borja en Huallamarca, y señaló que estos sitios se caracterizaban por ocupaciones ychsma.

Guerrero (2004) sostiene que hacia fines del Horizonte Medio existió una fuerte relación entre las áreas de Huaura-Chancay y RímacPachacamac, que daría lugar a que los estilos del Horizonte Medio influyeran en los nuevos que se estaban formando en los valles de Huaura y Rímac: Chancay e Ychsma respectivamente. Así, en el periodo Intermedio Tardío, los ychsma ocuparán los valles bajos de los ríos Rímac, Lurín y Mala.

Al igual que en el caso de la costa norte, este período aún no ha sido bien definido, como menciona Vallejo:

"Aunque el periodo Intermedio Tardío (PIT) en la costa central ha sido ampliamente tratado en diversos trabajos, es claro que aún estamos lejos de una comprensión cabal del mismo en términos de precisar por ejemplo sus inicios y cuando es el momento de ruptura con el Horizonte Medio. De hecho, este problema ha sido abordado puramente desde el punto de vista de estilos cerámicos y aun en este caso falta mucha precisión y concordancia al respecto. No es el único problema por supuesto que presenta serias interrogantes, la caracterización misma del periodo Intermedio Tardío en torno al desenvolvimiento temporal del mismo y como las sociedades involucradas se desarrollan en términos económicos y sociales resulta hasta el momento un ministerio" (2008: 84).
En general, la falta de información en el registro arqueológico y la falta de consenso entre las interpretaciones de los investigadores impiden conocer qué ocurrió durante el tránsito del Horizonte Medio al Intermedio Tardío en la costa peruana, lo que dificulta a su vez el entendimiento del desarrollo metalúrgico en este periodo.

\section{LA ORFEBRERÍA DE LA COSTA NORTE}

En la costa norte se desarrollaron una serie de técnicas orfebres que hicieron posible la elaboración de las piezas de metal que se encontraron en las numerosas tumbas de esta zona, sea mediante excavación arqueológica o por huaquería. Sin temor a exagerar, se puede afirmar que en la costa norte se desarrollaron todas las técnicas orfebres usadas por los antiguos peruanos en el área andina y se elaboraron todas las formas de objetos que se conocen en la orfebrería precolombina. Durante el Intermedio Tardío el oro, la plata, el cobre y las aleaciones como el bronce y la tumbaga sirvieron para elaborar piezas tanto suntuarias como utilitarias.

En el Intermedio Temprano, los vicús trabajaron mucho el cobre y el cobre dorado para elaborar piezas, principalmente laminadas y vaciadas. Más tarde, los orfebres mochicas se especializaron en la manufactura de objetos de metal de una fineza que asombra. Ellos heredaron este arte de sus antecesores, los vicús, pero supieron mejorarlo e innovarlo con nuevas técnicas.

En los últimos veinticinco años han proliferado las excavaciones arqueológicas en varios sitios moche; estos trabajos están permitiendo entender mejor dicha cultura, y particularmente la tecnología metalúrgica. Las excavaciones en Huaca Rajada (Alva 2004, 2008) han sido ampliamente difundidas a partir del descubrimiento de la tumba del Señor de Sipán. Este personaje fue enterrado con una gran cantidad de piezas de oro, plata y cobre, pero sobre todo de cobre dorado, siendo abundante el repertorio de formas, entre ellas orejeras, pectorales, cetros, chalchalchas, protectores coxales, narigueras, collares, adornos frontales y otros. 
Dos Cabezas es otro sitio moche, ubicado en el valle de Jequetepeque. Fue investigado por Donnan (2007), quien excavó varios contextos funerarios que contenían una serie de objetos de oro, plata, cobre y cobre dorado que acompañaban a los individuos principales, siendo la Tumba 2 -perteneciente a un hombre de 18 a 20 años de edad- la que tenía mayor número de artefactos de metal, entre ellos cuatro cinceles de cobre colocados en su mano derecha y uno de oro-cobre-plata en su mano izquierda. Según su forma y tamaño, Donnan sostiene que pudieron haber sido usados para el trabajo en metales, lo que hace de este un hallazgo muy importante, porque como indica este autor:

"No chisels have ever before been excavated in the hands in Moche burials. Why they were in his hands, what they signified, and whether they were his or belonged to someone else are questions that cannot be answered on the basis of available information" (Donnan, 2007: 113).

Llama la atención que ambas manos sostengan cinceles, isignificará esto que el personaje fue ambidiestro, es decir, que manejó el arte orfebre con las dos manos por igual?

Guerrero excavó contextos similares en el cementerio de Rinconada, La Molina, en Lima. En el sector IIA del sitio se localizaron entierros de orfebres en cuyo ajuar funerario se encontraron cinceles y otros instrumentos relacionados con el trabajo de metales. Es posible que el entierro mochica de Dos Cabezas también se trate de un individuo dedicado a la orfebrería pues hemos mencionado en otros trabajos (Carcedo y Vetter 2002) que estos artesanos elaboraban sus propios instrumentos y era muy raro que los regalaran o cedieran a otra persona porque se creía que estas herramientas adquirían las mañas de sus propietarios y no era posible eliminarlas. Es decir, cuando los usuarios elaboran estos instrumentos los confeccionan de acuerdo al tamaño y la postura de sus manos, de ahí que otra persona no pueda utilizarlos. Los hallazgos de este tipo de contextos funerarios resultan muy atrayentes porque son escasos y porque permiten estudiar los instrumentos en relación a los individuos, ya que la mayoría de herramientas que se encuentran en distintos tipos de colecciones provienen de huaquería.

En la Huaca El Pueblo, al sur de Lambayeque, Bougert (2009) descubrió la tumba de un individuo que denominó el Señor de Úcupe. Este personaje tenía más de 170 piezas de metal de cobre, cobre dorado y algunas pocas de plata y oro. Entre los objetos se encuentran una serie de adornos frontales, máscaras, miniaturas, túnicas, orejeras, escudos, coronas, collares, narigueras, entre otros.

Más al Sur, en las Huacas de Moche, en el valle del mismo nombre, se excavaron contextos funerarios de individuos cuyo ajuar incluía piezas de metal, pero no tenían la calidad ni cantidad que los sitios anteriormente nombrados (Morales 2004).

Por último, la Señora de Cao -descubierta en la huaca del mismo nombre en el Complejo El Brujo, del valle de Chicama- es otro individuo de élite mochica que tuvo un ajuar funerario muy rico en piezas de metal (Mujica 2007; Franco 2008).

Hasta la fecha no se han descubierto entierros de élite con abundantes objetos de metal, que daten de fines de la hegemonía moche (Moche Tardío para el norte o Moche V para el sur). El Proyecto Arqueológico San José de Moro excavó tumbas del periodo Mochica $\mathrm{V}$, como aquellas tan bien conocidas de las sacerdotisas, pero su director es claro al afirmar que en esta época el número de ofrendas de metal disminuyó notablemente (Castillo 2000: 20-21). Las piezas de metal encontradas en las tumbas asignadas a Mochica $\mathrm{V}$ son escasas y el metal usado generalmente fue el cobre, ambas características difieren de aquellas de las tumbas excavadas más al norte, en los periodos anteriores, como es el caso de Sipán (Alva 2004, 2008) o Úcupe (Bourget 2009).

La escasez de piezas de metal de gran calidad en San José de Moro a fines del periodo Moche es un tema que debe ser estudiado. ¿Por qué los contextos funerarios de élite de Mochica Temprano y Medio contienen una gran cantidad de objetos de metal con una rica iconografía y diversas formas, además del uso de diferentes 
metales y aleaciones? ¿Por qué desaparecen este tipo de contextos ca. 700 d.C.? Los estudios disponibles a la fecha no presentan evidencias claras del tránsito del Horizonte Medio al Intermedio Tardío en la costa norte, hace falta más excavaciones que proporcionen evidencias que permitan comprender la aparición de la cultura Sicán en el territorio que alguna vez fue ocupado por los Mochica del Norte y la cultura Chimú ubicada en lo que fue territorio de los Mochica del Sur.

La cultura Sicán (750-1375 d.C.) se desarrolló en Lambayeque, siendo su centro políticoreligioso Batán Grande en el valle de La Leche. Los sicanes heredaron de los mochica el arte del trabajo en metal y continuaron confeccionando piezas maravillosas, finamente trabajadas en oro, plata, cobre, y aleaciones como tumbaga y bronce arsenical. Estas piezas fueron elaboradas con fines suntuarios y utilitarios, y el repertorio es impresionante: abundan tocados, orejeras, narigueras, coronas, diademas, collares, estandartes, vasos de muchas formas, máscaras, guantes, herramientas multiuso, "naipes" y "plumas", entre muchas formas más (Carcedo 1998, 2005, 2007; Carcedo y Shimada 1985; Griffin y Shimada 1994; Elera 2008; Shimada y Griffin 1994; Shimada et al. 2000; Vetter 2006).

La riqueza en ofrendas de metal de la Tumba Este de Huaca Loro en Batán Grande -así como la de las piezas procedentes de este sitio que se encuentran en distintas colecciones del Perú y el extranjero- da una idea clara del tipo de objetos que los orfebres sicanes podían elaborar, así como las numerosas técnicas, metales y aleaciones que utilizaron (Shimada 1995).

Recientes excavaciones arqueológicas en el Complejo Chotuna-Chornancap en Lambayeque, dan cuenta del descubrimiento de tumbas de élite de la cultura Sicán o Lambayeque donde se aprecian, como parte de sus ofrendas funerarias, máscaras, cetros, orejeras, coronas, entre otros objetos (El Comercio 2011).

Un poco más tarde y hacia el sur se desarrolló la cultura Chimú (1200 - 1470 d.C.) en el departamento de La Libertad, con su centro en la ciudadela de Chan Chan, localizada en el va- lle de Moche. Los chimú dejaron de lado el oro y el cobre para dedicarse casi exclusivamente a la elaboración de piezas de plata. Los objetos manufacturados por los grandes orfebres chimú son casi los mismos que fabricaron sus antecesores, y entre ellos destacan particularmente los vasos, tanto los de forma de cubilete como los de tipo copa-sonaja, muchos de ellos con una rica iconografía que representa diferentes temas.

El Museo Nacional de Arqueología, Antropología e Historia del Perú (MNAAHP) en Lima alberga a la colección Dalmau, procedente de Trujillo, que fue decomisada en la década de 1930 y que está formada por sesenta y un vasos de plata -algunos incompletos- con forma de cubilete, elaborados con la técnica del recopado y cuya iconografía representa imágenes marinas y de pesca realizadas con la técnica del repujado. Castillo (2009) realizó la conservación de tres de estos vasos, además de una serie de análisis que permitieron determinar la forma de manufactura y la aleación usada.

Ríos y Retamozo (1982) realizaron un estudio iconográfico y de manufactura de 20 vasos -dieciséis de plata y cuatro de oro- procedentes de Chan Chan, que se encuentran en custodia del MNAAHP. Estos vasos provendrían de la Huaca de la Misa, una plataforma funeraria donde aparentemente se encontró una gran cantidad de piezas suntuarias. Los vasos fueron elaborados a partir de cinco partes: copa, parte central, base y dos piezas pequeñas que sirvieron para el acoplamiento. Las técnicas para elaborar y decorar estos objetos fueron: laminado, calado, repujado, recopado, soldadura y unión mecánica. La iconografía está relacionada con el mar, resaltando las actividades de pesca, los peces y las aves marinas.

Las orejeras y narigueras de plata que se encuentran en el Museo Larco de Lima muestran la rica iconografía que los chimú plasmaron en este tipo de piezas. Casi todas fueron elaboradas con las técnicas del calado y repujado, dando vida a las escenas que los orfebres querían plasmar en ellas. Otro tipo de objetos que destacan especialmente son las miniaturas. En las colecciones del Museo Larco y el Museo de Oro, ambos de Lima, se encuentran objetos en miniatura, casi todos 
elaborados mediante el laminado y el recortado, y en plata. Las miniaturas representan escenas fúnebres, como un cortejo funerario que lleva en hombros al difunto, o también escenas relacionadas con la elaboración de textiles.

Aunque la orfebrería involucra piezas elaboradas en oro y plata, existe un tipo de objeto que debe ser tomado en cuenta en este estudio porque es confeccionado con metal y porque hasta el momento no está presente en el registro arqueológico de la costa central: es la herramienta multiuso que aparece en la costa norte durante el periodo Intermedio Tardío. Los sicanes la elaboraron con bronce arsenical, lo que permitió un incremento de la producción, una extensión de las vías de comunicación, una ampliación de los sitios administrativos y ceremoniales, y un incremento del flujo y la calidad de los productos exóticos intercambiados en todo el norte de los Andes Centrales. Estos implementos conocidos como puntas y rejas insertadas en mangos de madera para formar barretas y barretillas continúan en uso hasta el presente (Hocquenghem 2004; Hocquenghem y Vetter 2005; Mayer 1998). (Figura 1)

Estas herramientas fueron elaboradas mediante el vaciado y luego fueron martilladas. El Proyecto Arqueológico Sicán excavó un conjunto de hornos de fundición de cobre arsenical en los que se realizó la aleación para la fabricación de este tipo de implementos, además de "naipes" y "plumas" (Bezúr 2003; Vetter 1993, 1996; Vetter et al. 1997).

\section{LA ORFEBRERÍA DE LA COSTA CENTRAL}

La orfebrería de la costa central se caracteriza por piezas elaboradas en láminas repujadas, máscaras, vasos, cuencos, pinzas, cucharas de rapé, tupus, agujas, anzuelos, anillos y collares, así como pocos objetos más (Baessler 1906; Carcedo et al. 2004; Cárdenas 1975; Hudtwalcker 2009; Reiss y Stübel 1998; Ríos y Retamozo 1978; Squier 1974; Vetter 2004; Vetter y Villacorta 2001; Wiener 1983). El metal más usado para la elaboración de estas piezas fue la plata, aunque hay evidencias de uso del cobre y oro en menor proporción, además del cobre dorado. Asimismo, la lista de las técnicas empleadas por los orfebres de la costa central es reducida, pues mayormente utilizaron laminado, repujado, recortado, recopado, grabado, soldadura en pocos casos, unión mecánica y también vaciado (Carcedo et al. 2004; Vetter 2004; Vetter y Villacorta 2001).

Si bien en los últimos años hubo un aumento considerable de las investigaciones y publicaciones de los trabajos arqueológicos en la costa central y surcentral, aún no hay trabajos sobre tecnología metalúrgica. Son muy pocos los estudios que ofrecen información sobre objetos y las técnicas con las que fueron elaborados (Carcedo et al. 2004; Carcedo y Vetter 2002; Ríos y Retamozo 1978; Vetter 2004; Vetter y Villacorta 2001). La escasez de información arqueológica limita también el estudio de los objetos de metal provenientes de huaquería pues no permite ubicarlos en un periodo u otro, lo cual es una gran desventaja dada la similitud entre los objetos del Intermedio Tardío y los del Horizonte Tardío. Son muy pocos los datos que un objeto de metal de la costa central podría ofrecer para realizar una seriación pues la mayoría son formas que datan de periodos anteriores, como es el caso de los tupus, anzuelos, agujas, anillos, collares, etc. Afortunadamente en el caso de los vasos y cuencos, la iconografía que suelen presentar, -sea repujada o grabada- permite asignar una cronología aproximada.

A diferencia de lo que sucede en la costa norte, en la costa central existen muy pocos datos que ayuden a develar el proceso metalúrgico en el Intermedio Tardío, y en general en todos los periodos. Muchas de las investigaciones arqueológicas en la costa central, incluso en sitios tan importantes como Cajamarquilla en el valle del Rímac y Pachacámac en el valle de Lurín, no han sido publicadas. En los últimos años, los investigadores están esforzándose en presentar propuestas que apunten hacia un entendimiento de su proceso cultural (Eeckhout 2004a). La falta de investigaciones y de difusión de las mismas ha contribuido a limitar los trabajos relacionados con los metales.

Las recientes excavaciones del Proyecto de Rescate Arqueológico Loop Costa -realizadas en el marco de los trabajos de ampliación del gasoducto de Camisea entre Pampa Melchorita 


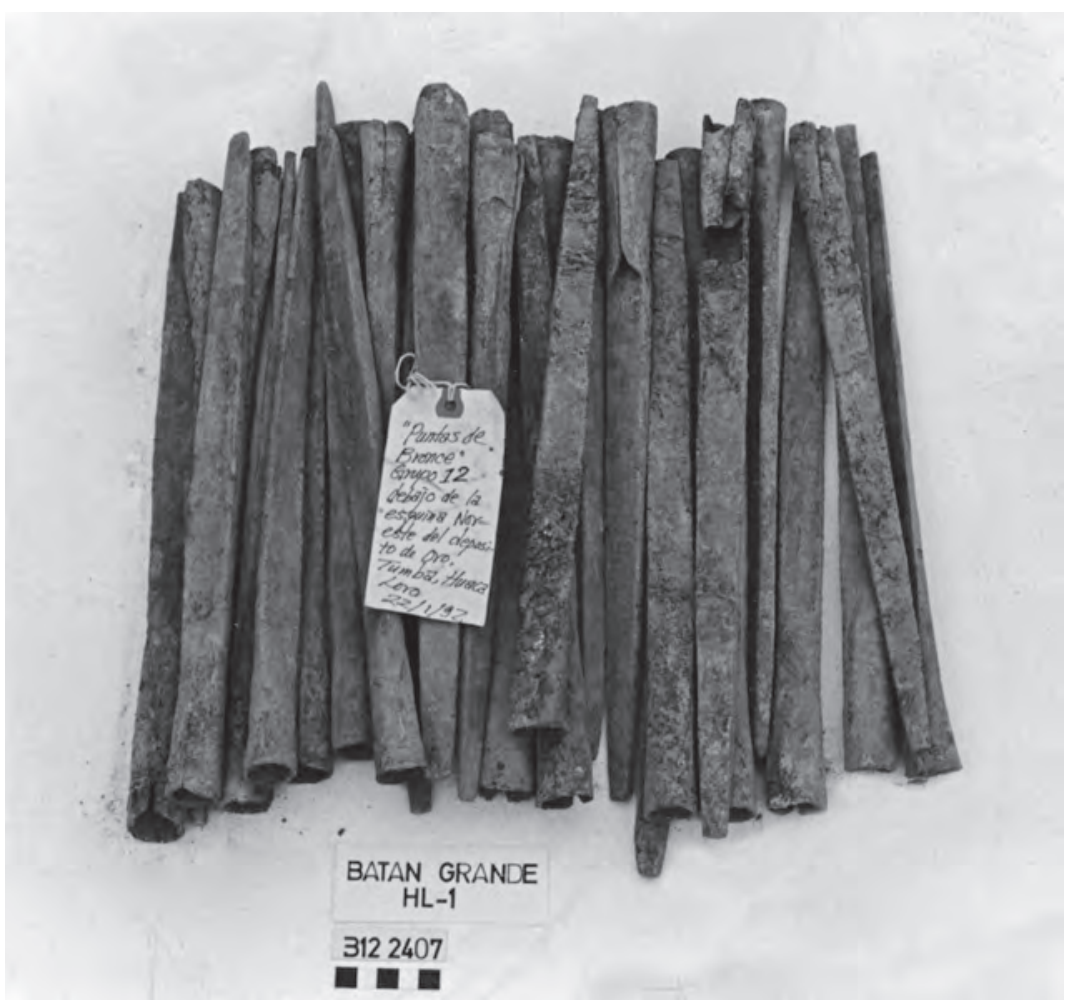

Figura 1. Puntas de cobre arsenical de la Tumba Este de Huaca Loro en Batán Grande. (Fotografía: Luisa Vetter)

y Lima- han recuperado una considerable cantidad de piezas de metal. Uno de los sitios excavados que presenta dichas evidencias es Higueras 1-Sector Suroeste, perteneciente al Intermedio Tardío según las investigaciones y análisis aún en curso (TgP 2009).

Este sitio arqueológico se encuentra ubicado en el distrito de Chilca, provincia de Cañete, departamento de Lima, a la altura del kilómetro 66 de la carretera Panamericana Sur y en la margen izquierda de la quebrada Las Higueras (Figura 2). El sitio está conformado por un conjunto de trece conchales o montículos de un tamaño promedio de $40 \mathrm{~m}$ de diámetro por 3 a $4 \mathrm{~m}$ de altura y compuestos principalmente por valvas de Mesodesma donacium (machas). En superficie se observan restos de material cerámico, óseo, botánico y textil. Los trabajos de rescate arqueológico se realizaron en los montículos 1, 2, 3, 4 y 5. (Figura 3)

La primera ocupación de estos montículos corresponde a restos de estructuras domésticas asociadas a abundantes hoyos que contenían material diverso, a manera de pequeñas ofrendas (Figuras 4 y 5). Los hoyos tuvieron un uso continuo y prolongado pues algunos intruyen los surcos que forman la base de las estructuras de quincha, aunque estos surcos también intruyen algunos hoyos, así como ciertos hoyos intruyen a otros, lo que confirma que estuvieron en uso antes y después de la ocupación doméstica. Luego del abandono de esta ocupación, los conchales comenzaron a formarse por la superposición de distintas capas con restos de áreas de quema con concentraciones de ceniza, material malacológico, carbón, restos botánicos, metales, textiles, coprolitos, artefactos óseos y líticos, además de escasos entierros humanos y de animales (Figura 6 y 7$)$.

Entre los objetos de metal recuperados en Higueras 1-Sector Suroeste se encuentran algunos de uso utilitario y otros personales, siendo los más recurrentes: pinzas, anzuelos, agujas y tupus, 


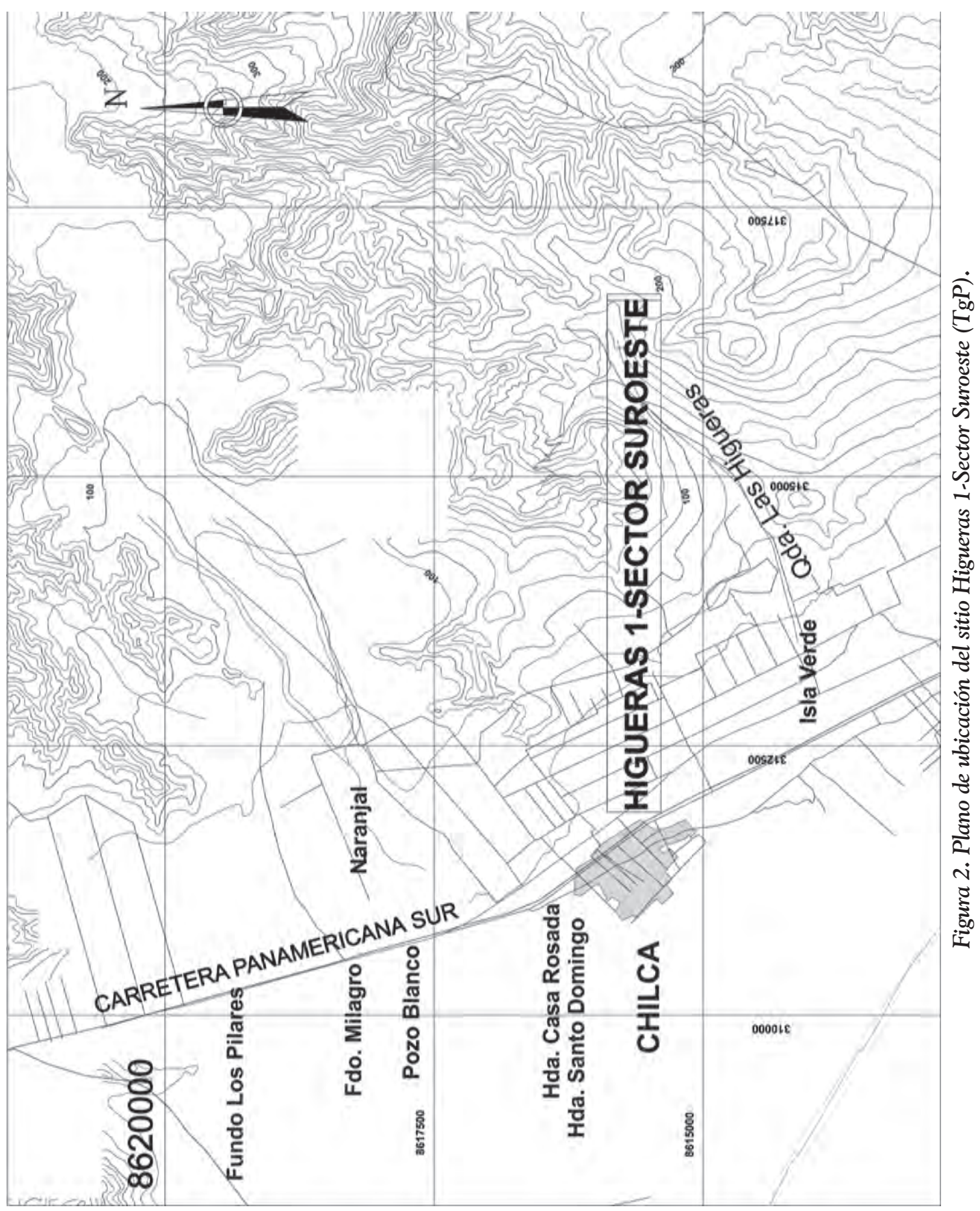




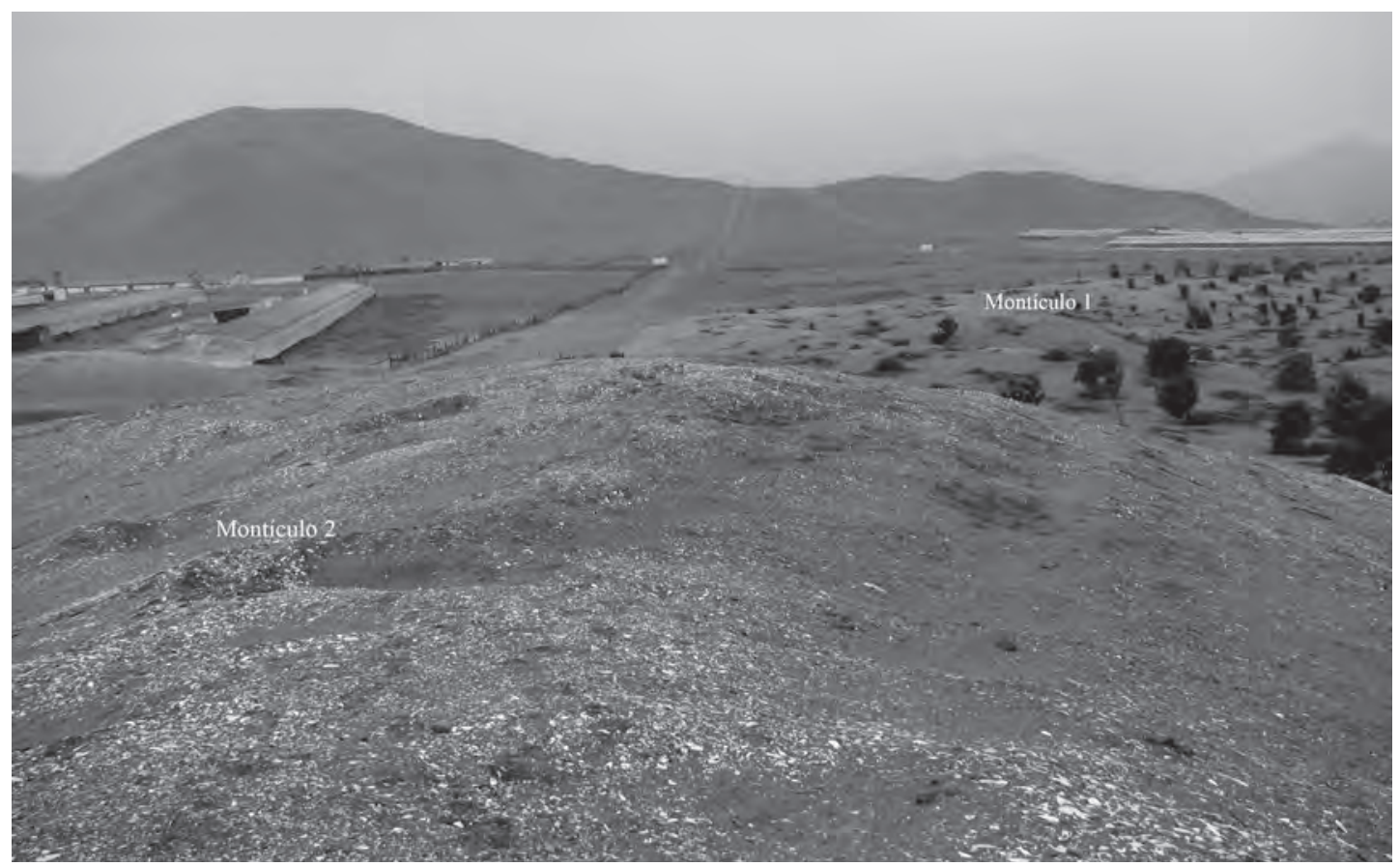

Figura 3. Vista de los Montículos 1 y 2 (conchales) antes de la excavación, vista del Noroeste al Sureste (TgP).

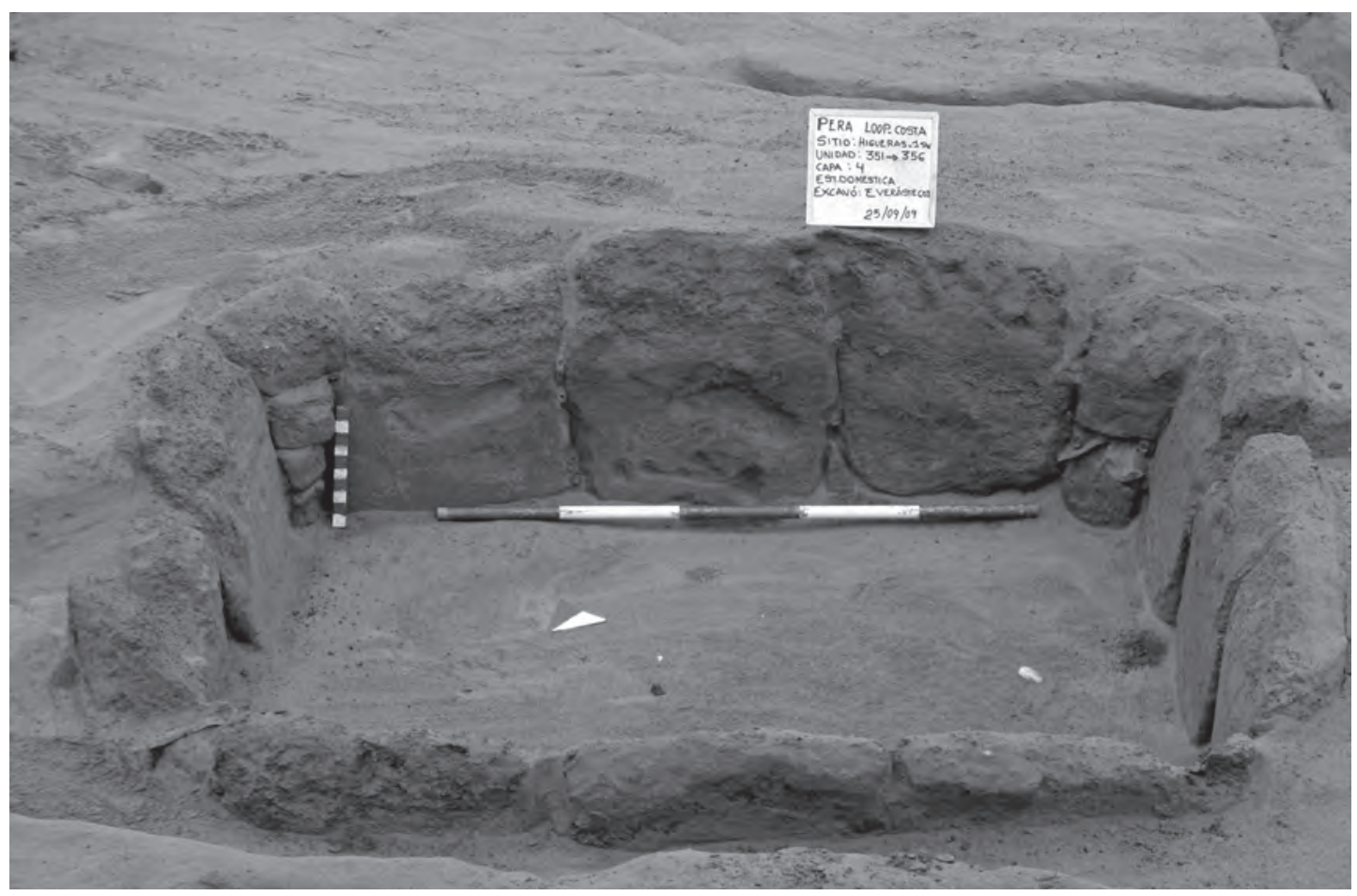

Figura 4. Área doméstica (TgP). 


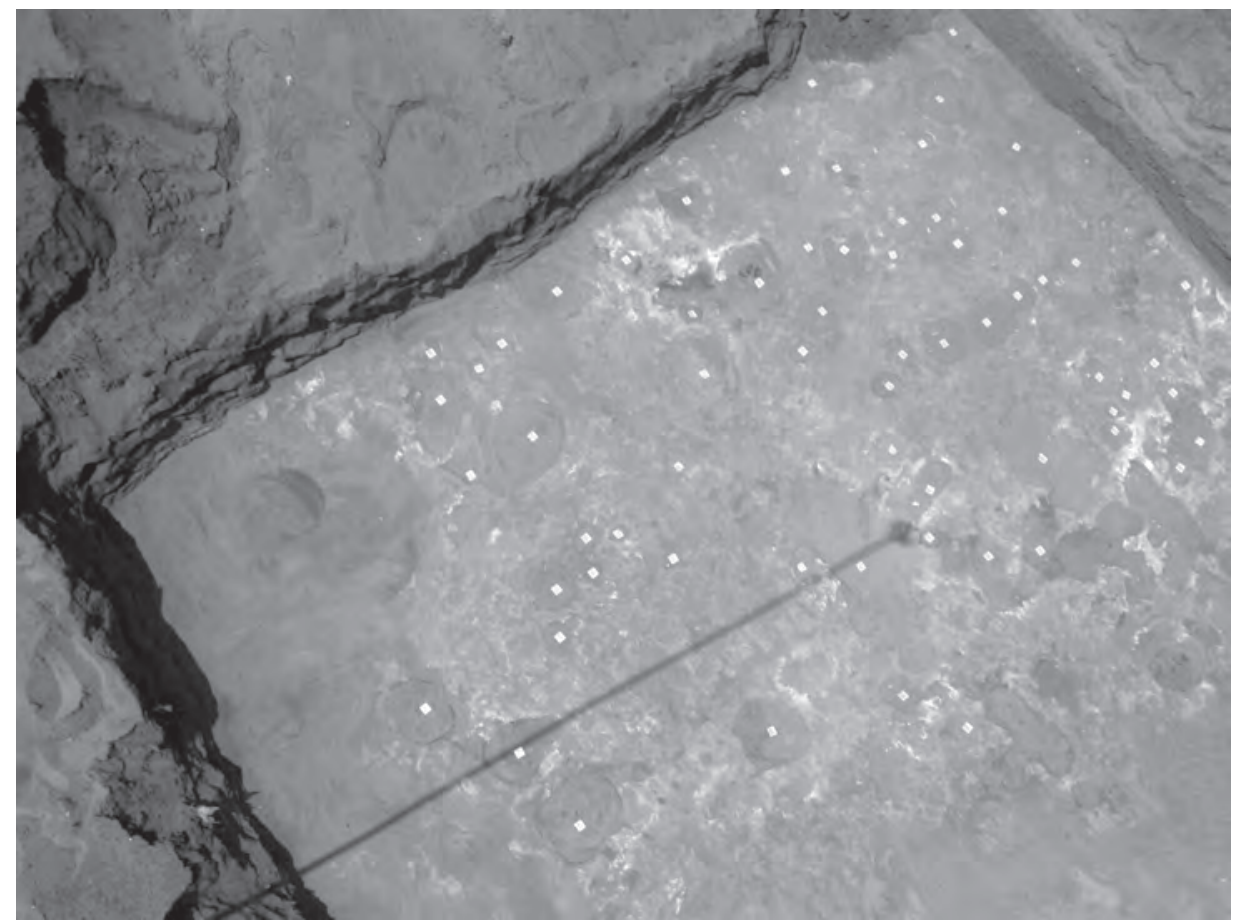

Figura 5. Evidencia de los hoyos que habrían sido usados para depositar ofrendas (TgP).

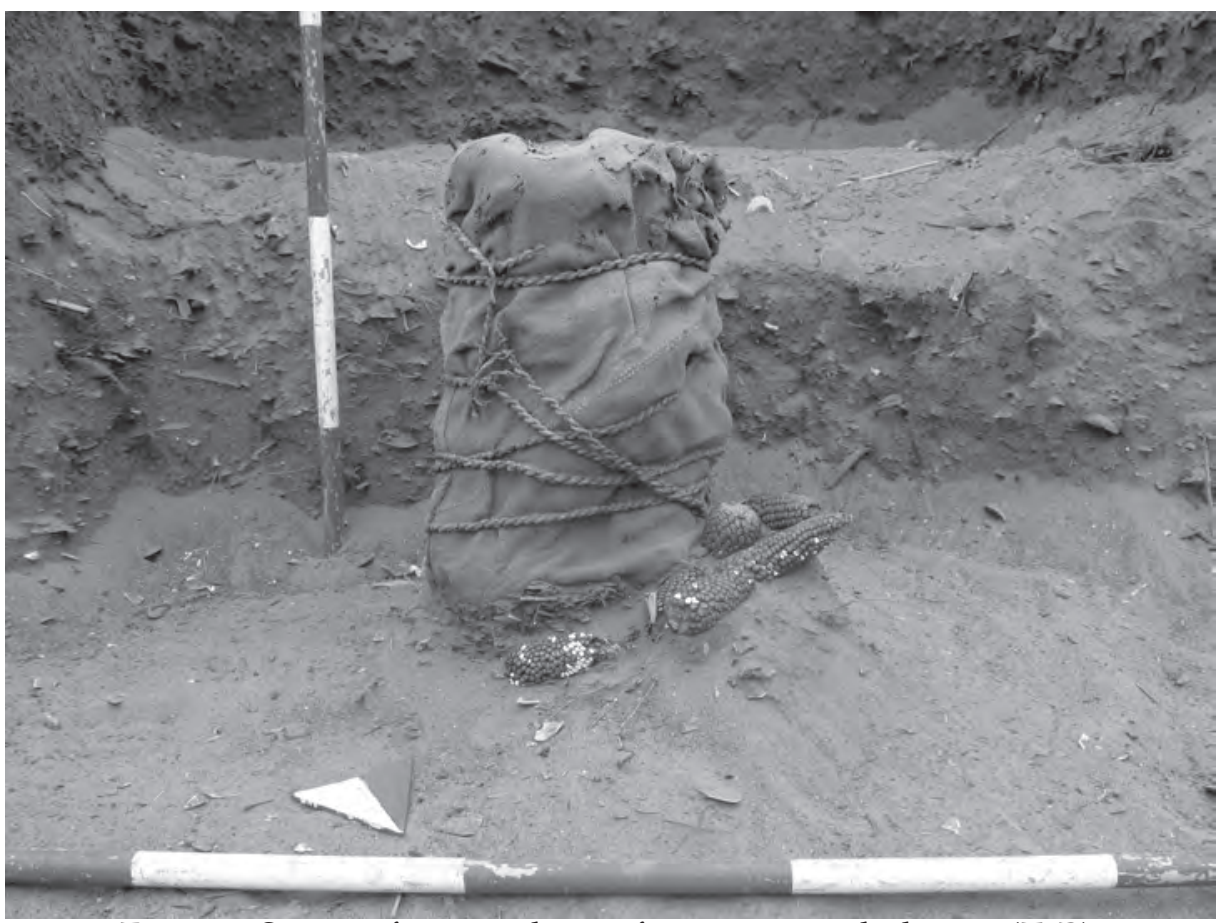

Figura 6. Contexto funerario de un infante acompañado de maíz (TgP). 


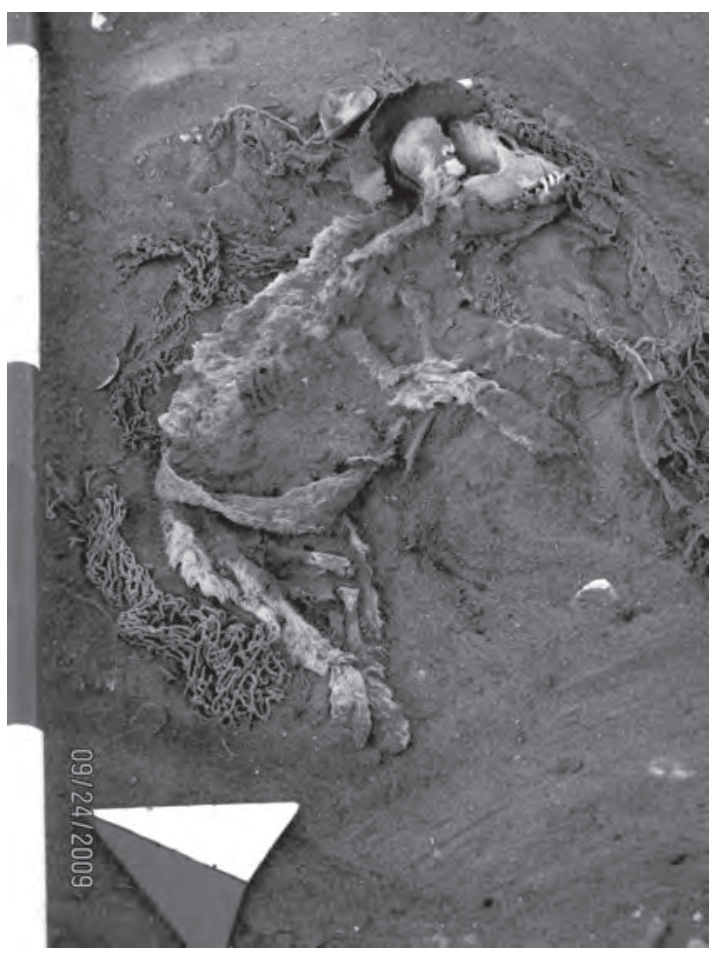

los cuales fueron confeccionados posiblemente con cobre o bronce, y con las técnicas del vaciado y laminado. ${ }^{1}$ Llama la atención la cantidad de estos objetos: sesenta y dos anzuelos (Figura 8 ), cuarenta y un tupus (Figura 9), cinco pinzas ${ }^{2}$ (Figura 10) de diversos tamaños y de forma circular, y seis agujas (Figura 11) de diferente tamaño, además de una gran cantidad de piezas fragmentadas cuyo uso no puede ser definido hasta el momento. La mayor cantidad de piezas provienen del Montículo 2.

La mayoría de estos objetos están relacionados con las actividades de pesca y la confección y reparación de las redes. Esto se complementa con

1 Este material es analizado por Álvaro Acevedo para su tesis de Licenciatura en Arqueología por la Universidad Nacional Mayor de San Marcos, investigación que incluirá el estudio arqueométrico de las piezas de metal, siendo la autora la asesora externa de dicha tesis.

2 La mayoría de investigadores denominan depilador al instrumento que sirve para sujetar algún objeto y que tiene diversas formas y es hecho de diferentes materiales y cuyos extremos se aproximan como sujetador. En realidad, este objeto debería denominarse pinza, ya que el depilador se relaciona más a un instrumento que se usa para retirar el vello.
Figura 7. Contexto funerario de un cánido. La cabeza se encuentra cubierta por textiles y el cuerpo con malla y faja en la zona pélvica (TgP).

la abundancia de objetos de madera identificados como flotadores, así como instrumentos y fibras para tejer (palillo de huso, espada de tejedora, esteras, petates, cordeles y soguillas). Squier halló en Pachacámac un entierro de una familia compuesta por los padres y tres niños. El padre fue hallado con una red de fibra entrelazada del agave cuyas mallas estaban muy bien anudadas, lo que llevó a Squier a interpretar que el individuo era un pescador pues también tenía sedales de diversos tamaños, algunos anzuelos de cobre con lengüetas y algunas plomadas de cobre, y alrededor del cuello colgadas de un hilo se encontraron un par de pinzas de bronce, según Squier para arrancarse la barba (1974: 39). Llama la atención que se encuentren juntos implementos de pesca y un par de pinzas en el entierro de un individuo de sexo masculino, lo que lleva a pensar que probablemente estos objetos eran de uso masculino.

El conjunto de piezas relacionadas con la pesca (anzuelos, agujas y pinzas) y los tupus, simbolizarían a dos grupos: el masculino vinculado con la actividad de pesca y el femenino vinculado a sus típicos adornos personales (Vetter y Carcedo 2009). La presencia de estos grupos de objetos de metal entre las capas de los conchales o montículos y también en los pozos del sitio habitacional, hace pensar en la posibilidad que estos objetos metálicos pudieron haber sido colocados allí como ofrendas que representaban actividades masculinas y femeninas, y no desechados como parte de la basura depositada en estos montículos. Creemos posible que los objetos y productos más valiosos se juntaban para ofrendarlos, sacrificarlos, sean de uso masculino o femenino. Esta idea se ve reforzada por el hallazgo de entierros humanos y de animales entre las capas de basura de los conchales, lo que podría indicar un uso ritual de los mismos.

Esta hipótesis encuentra apoyo en el conocimiento de que los objetos de metal eran un bien muy preciado por lo costoso de su elaboración. Primero era necesario identificar yacimientos de minerales o metales nativos, luego 


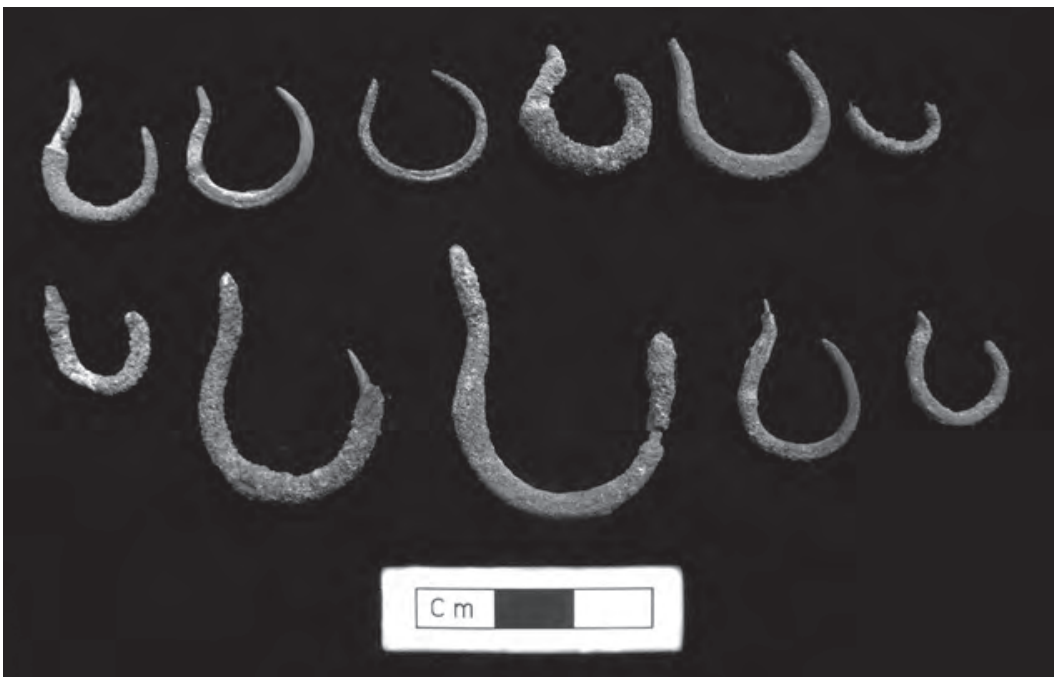

Figura 8. Algunos anzuelos del sitio Higueras 1-Sector Suroeste (Fotografía: Luisa Vetter, TgP).

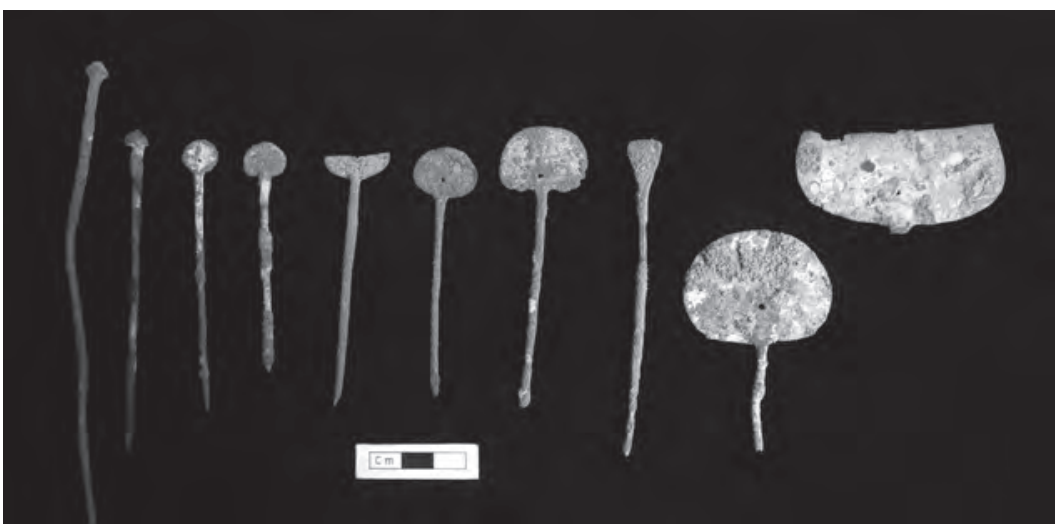

Figura 9. Tupus del sitio Higueras 1-Sector Suroeste (Foto: Luisa Vetter, TgP).

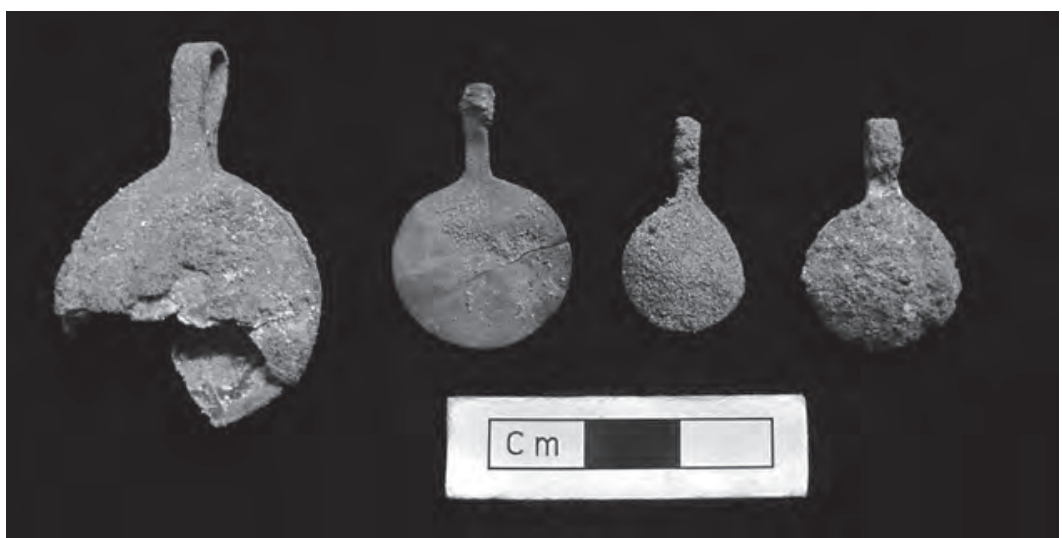

Figura 10. Pinzas del sitio Higueras 1-Sector Suroeste (Foto: Luisa Vetter, TgP). 


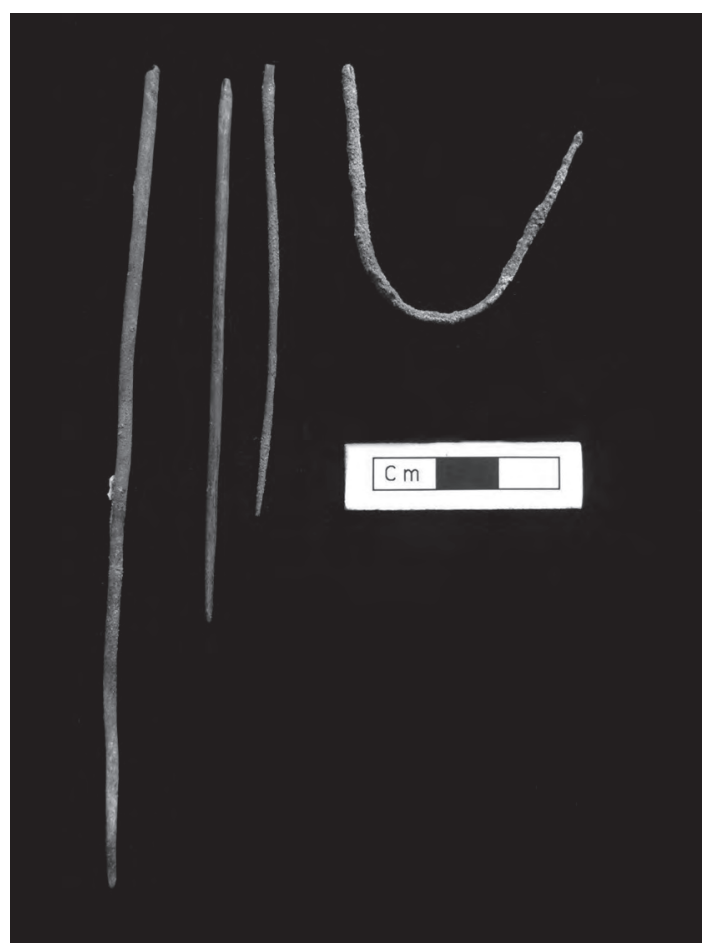

fundirlos y finalmente manufacturarlos con la forma y medidas requeridas para su uso, sea éste suntuario, personal o utilitario. Si un objeto de metal se quebraba o rompía, no era desechado como sí ocurría con la cerámica o la piedra, ya que el metal puede volver a fundirse y reutilizarse, ya sea para elaborar el mismo objeto o uno de forma o uso distinto. Un ejemplo de lo valioso que puede ser un desecho de metal es el que se encontró en la Tumba Este de Huaca Loro donde junto a casi doscientos kilos de implementos de cobre arsenical sin terminar se halló una gran cantidad de desechos de metal que según Shimada se componían de:

"pequeñas piezas, resultado del cortado, limado, y otras etapas del trabajo con láminas de metal precioso, incluyéndose objetos rechazados por errores en la manufactura... La presencia de tierra, espinas y hojas de algarrobo, y de tiestos en estas pilas, sugiere que este material fue recogido no sólo de las mesas de trabajo sino también del suelo de los talleres... Los orfebres de hoy en día lo conservan para volver a fundirlo agregándole oro para hacer nuevos lingotes". (1995: 95).
Figura 11. Agujas del sitio Higueras 1-Sector Suroeste (Foto: Luisa Vetter, TgP).

Por otro lado, los objetos de metal en el registro arqueológico se suelen asociar a eventos importantes, como por ejemplo la tumba de personajes de elite o gobernantes, o como ofrenda al cierre de un sitio arquitectónico.

La abundante cantidad de piezas de metal encontradas en este sitio induce a pensar que posiblemente en esa zona o cerca de ella se encontraban talleres de orfebrería donde las manos expertas de los orfebres elaboraban dichas piezas con las técnicas del vaciado y laminado, que son las predominantes según nuestras observaciones. En el Montículo 5 se encontró una tablilla de arcilla cocida cuyo centro tiene una concavidad con restos adheridos de óxido de cobre, y que probablemente fue un recipiente para el trabajo de metales. Sin embargo, también es posible que sean piezas que fueron elaboradas en otros sitios y que circularon como bienes suntuarios.

Hasta el momento, en la costa central no se conocen talleres de orfebrería como aquellos de Pampa de Burros en Lambayeque (Curay 2003) y Chan Chan en La Libertad (Topic 1990), ambos del periodo Intermedio Tardío, que nos permita conocer cómo se organizaban los orfebres en esta zona para confeccionar sus productos. iTrabajaban dentro de sitios habitacionales como en los talleres identificados en la costa norte? ¿Quiénes eran responsables de esa producción, los mismos orfebres o había una autoridad que les indicaba qué debían hacer y además les proporcionaba el metal? Estas interrogantes solo podrán ser contestadas con el hallazgo y registro de este tipo de sitios.

En el patio de la Pirámide con Rampa N. ${ }^{\circ}$ 2 de Pachacámac, Franco (2004) identificó un espacio designado para actividades relacionadas con la producción de objetos de metal. Desafortunadamente no hay una descripción de este hallazgo, ni se menciona la presencia de objetos que podrían apoyar esta interpretación, como herramientas de manufactura de piezas de metal, es decir, taces, cinceles, martillos, etc., o alguna evidencia de horno para el recalentamiento. 
Otro sitio que ha pasado desapercibido para los investigadores a pesar del hallazgo de piezas de metal es el conjunto de Huacas Pando en Lima. El Seminario de Arqueología del Instituto Riva-Agüero de la Pontificia Universidad Católica del Perú excavó entre 1964 y 1974 las huacas ubicadas entre la avenida La Marina por el Sur, la avenida Riva Agüero por el Oeste, la avenida Venezuela por el Norte y al Este con la Urbanización La Luz en la Prolongación 28 de Julio en Pueblo Libre (Figura 12). El conjunto denominado Huacas Pando comprende a: Huaca Palomino, Huaca Corpus I, Huaca Corpus II, Huaca La Luz I, Huaca La Luz II, Huacas o Montículos 17, 18 ,19 y 20, Huacas o Montículos 62, 63 y 64, Huaca Culebras o 65, Huaca Tres Palos, Huaca Colegio Juan XXIII y Huaca Casa Rosada. El Seminario de Arqueología del IRA-PUCP elaboró los Informes Preliminares 1969-1974 (Cárdenas, 1975, 2 tomos) que en estos momentos se encuentran en custodia del Museo de Arqueología "Josefina Ramos de Cox" IRA-PUCP, y los materiales culturales fueron exhibidos en la exposición permanente "Hatun Maranga", desde 1995 hasta 2006 en las salas del MAJRC en la Casa O'Higgins.
Según los estudios de Ramos de Cox (1970), las Huacas Pando tienen una larga secuencia de ocupación que abarca desde la aparición de la cerámica hasta fines del siglo XVI. En varias de ellas se encontraron objetos de metal, sobre todo correspondientes al Intermedio Tardío y a la ocupación colonial.

Una de las huacas en las que se encontró mayor cantidad de piezas de metal es La Luz I, donde se registraron láminas repujadas en forma de batracios y cabeza de serpientes de plata, placas de plata asociadas a textil, así como un vaso antropomorfo de plata y un vaso en forma de cubilete igualmente de plata, además de tupus de plata y otros de cobre, pinzas de diversas formas (algunas de ellas asociadas a textil), cucharas de rapé, un cuenco y algunos anillos (Cárdenas, 1975) (Figuras 13, 14, 15, $16,17,18,19)$.

Según Ramos de Cox (1970), Huaca La Luz I habría sido un centro artesanal o casa de enseñanza para luego convertirse en un cementerio del periodo Intermedio Tardío, con entierros secundarios de individuos relacionados al arte textil según el tipo de ofrendas encontradas. De

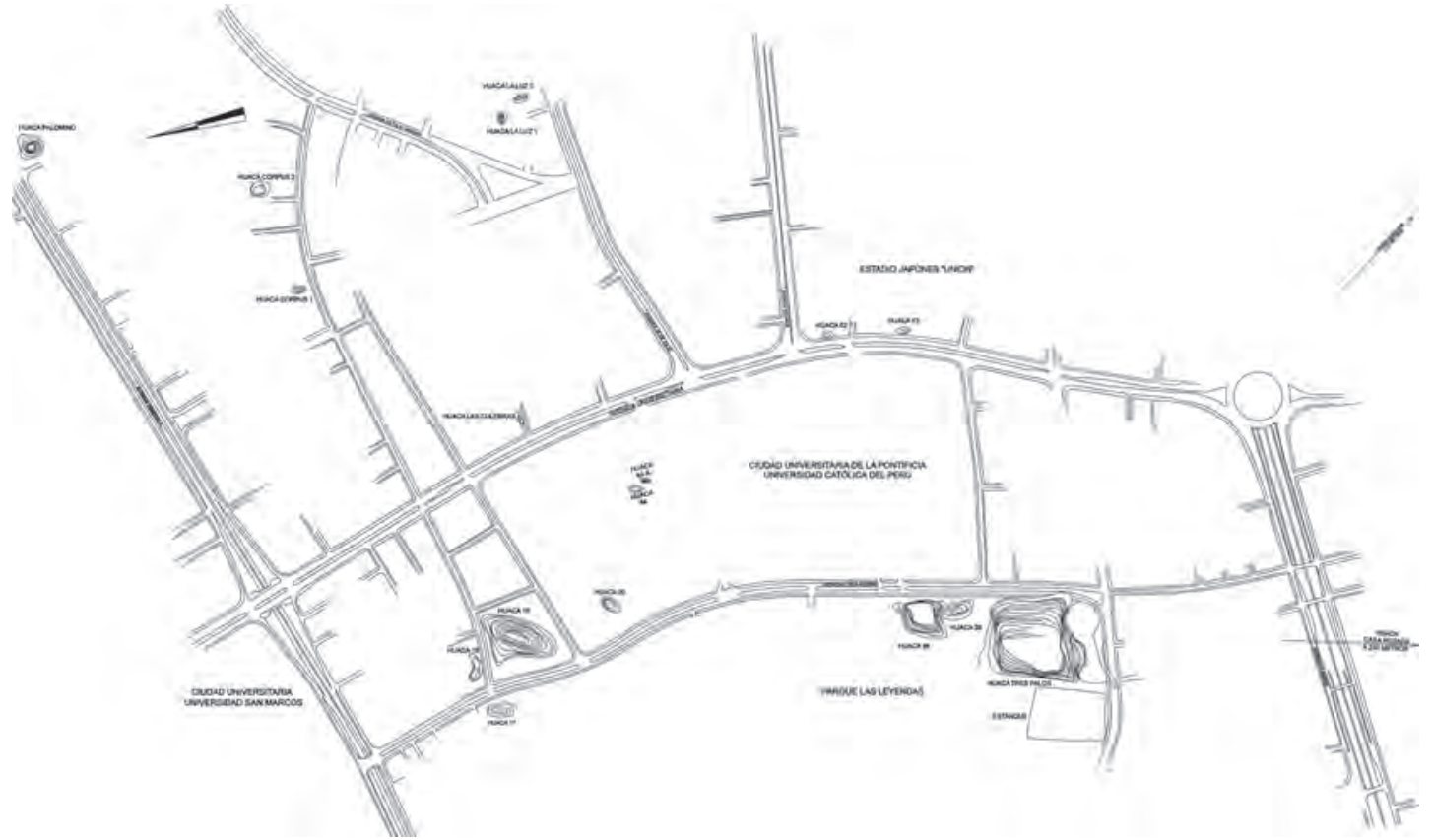

Figura 12. Plano de ubicación de las Huacas Pando (Seminario de Arqueología del Instituto RivaAgüero de la Pontificia Universidad Católica del Perú). 


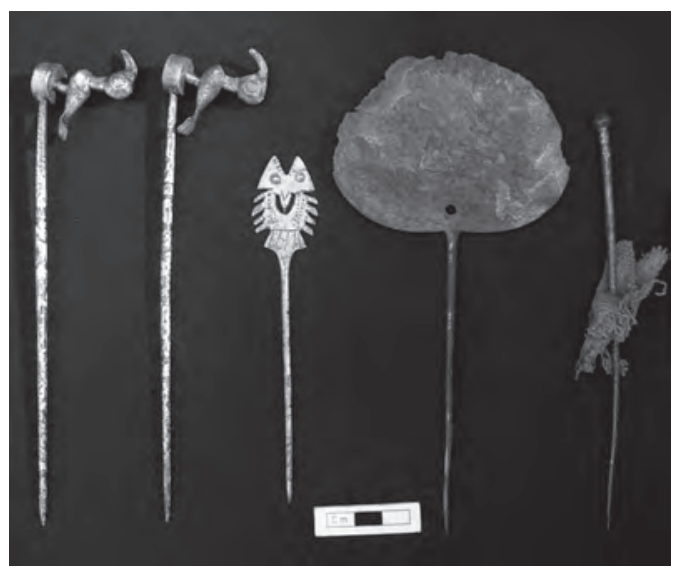

Figura 13. Tupus de Huaca La Luz I (Foto: Luisa Vetter. Museo de Arqueología Josefina Ramos de Cox).

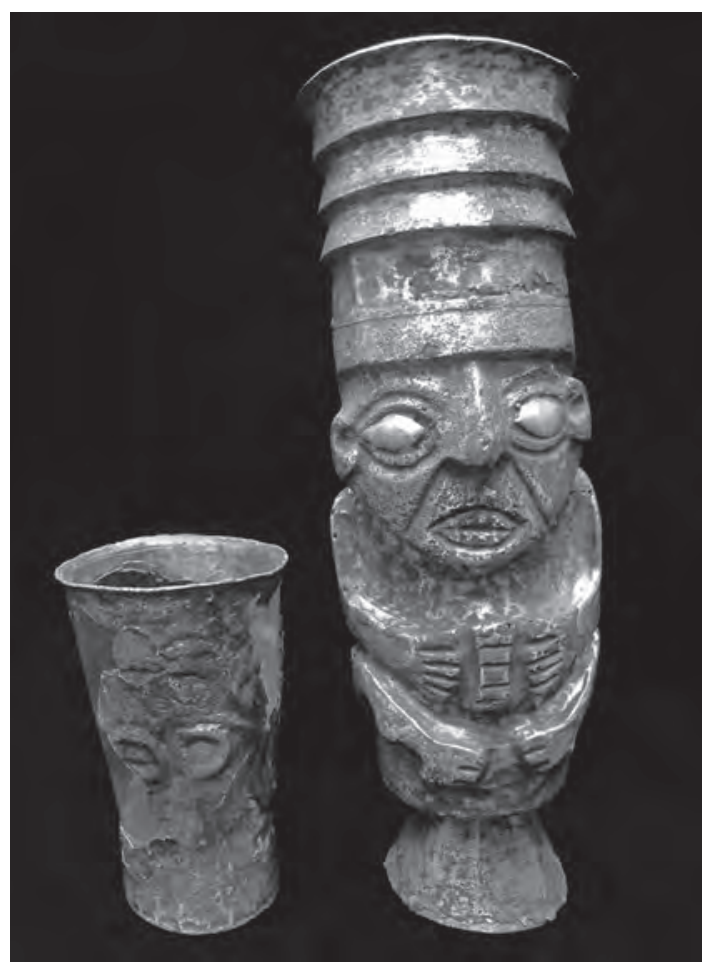

los sesenta y cinco entierros excavados, diecisiete tuvieron como ofrenda funeraria alguno de los objetos de metal ya señalados líneas arriba (Cárdenas 1975).

Uno de los contextos funerarios donde se halló mayor cantidad de piezas de metal fue el Entierro 52, en el que se registró:

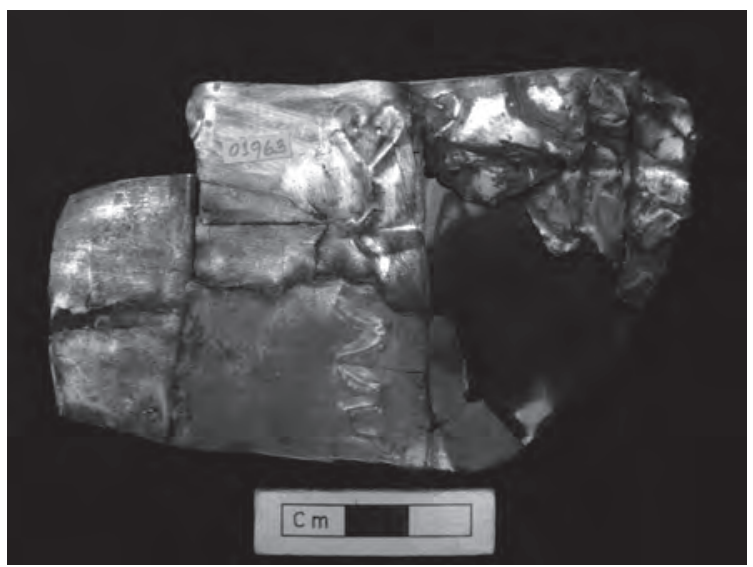

Figura 14. Placa repujada con cabeza de serpiente de Huaca La Luz I (Foto: Luisa Vetter. Museo de Arqueología Josefina Ramos de Cox).

Figura 15. Vaso antropomorfo y aquilla de Huaca La Luz I (Foto: Luisa Vetter. Museo de Arqueología Josefina Ramos de Cox).

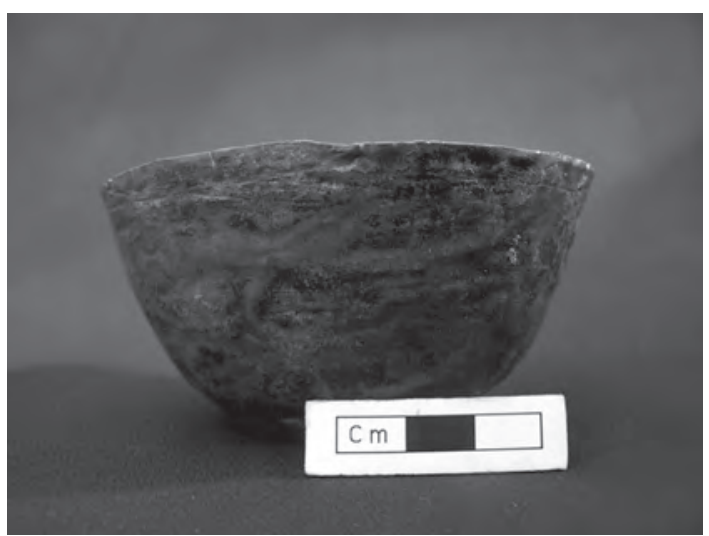

Figura 16. Cuenco de Huaca La Luz I (Foto: Luisa Vetter. Museo de Arqueología Josefina Ramos de Cox).

"restos humanos con cráneo orientado al oeste, adolescente, con huellas de pintura en el parietal y en la base de la nariz. Ofrendas de: vaso de metal con representación de cara, fragmento de metal, un segundo vaso de metal muy aplastado colocado entre las extremidades superiores, depilador de cobre, fragmento de tela, semillas de algodón dentro de un 


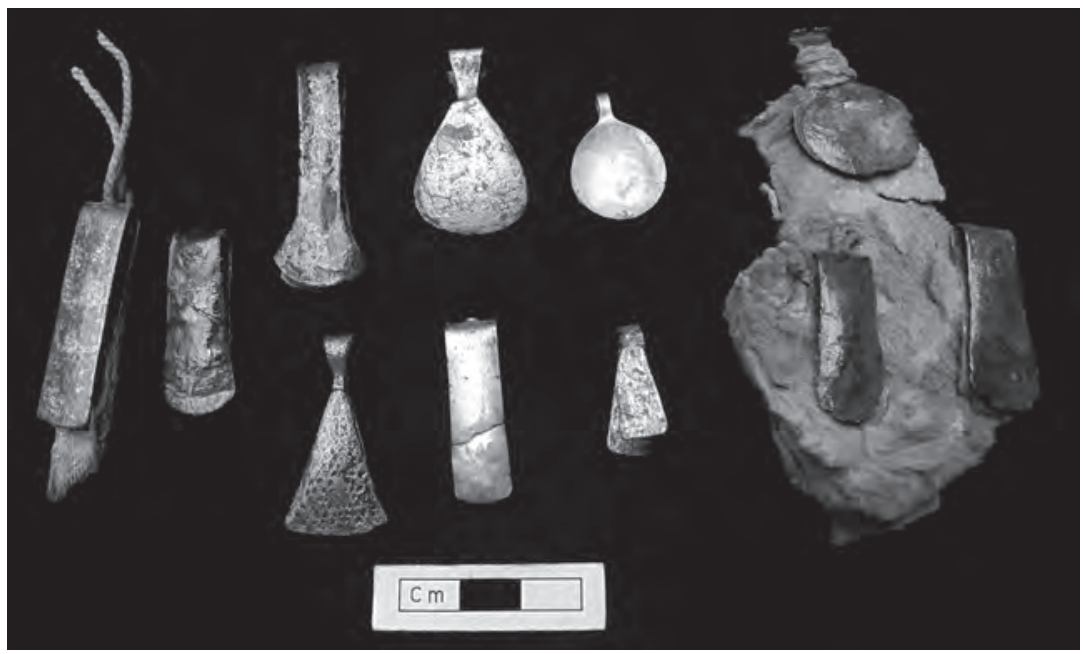

Figura 17. Pinzas de Huaca La Luz I (Foto: Luisa Vetter. Museo de Arqueología Josefina Ramos de Cox).

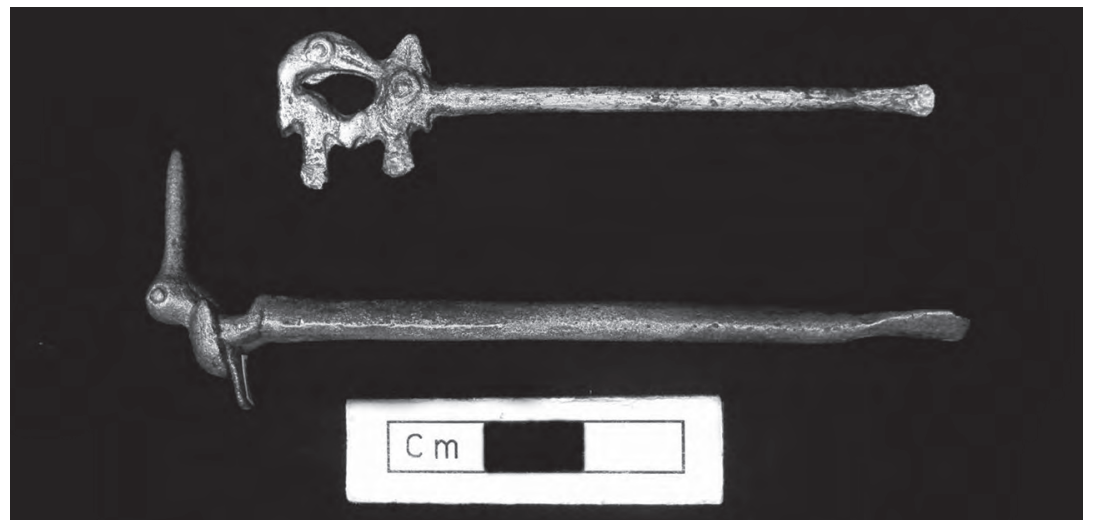

Figura 18. Cucharas de rapé de Huaca La Luz I (Foto: Luisa Vetter. Museo de Arqueología Josefina Ramos de Cox).

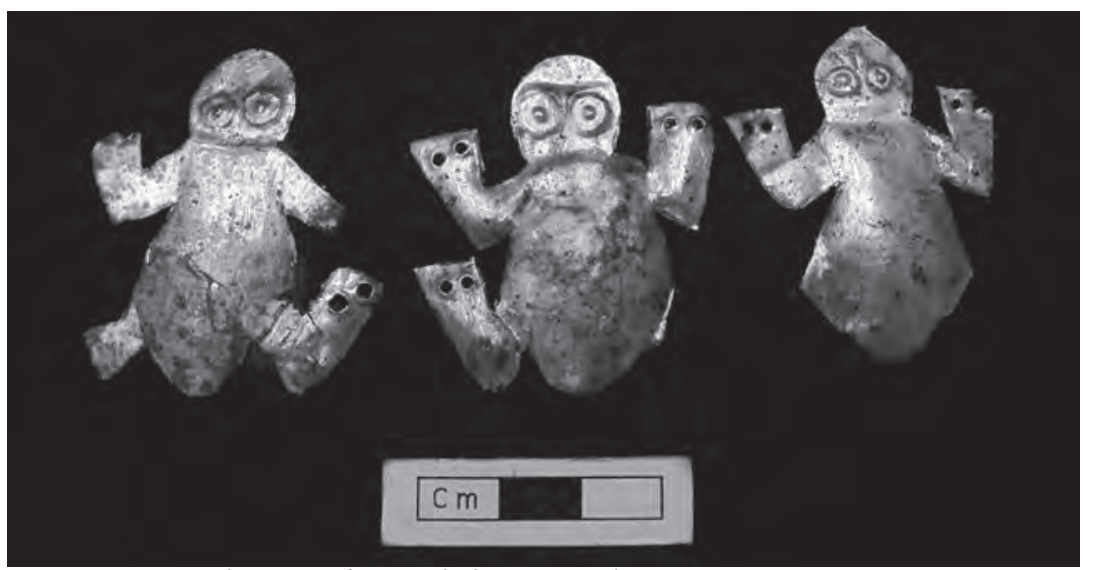

Figura 19. Placas en forma de batracios de Huaca La Luz I (Foto: Luisa Vetter. Museo de Arqueología Josefina Ramos de Cox). 
mate, semillas de maní dentro de otro mate, ceramio en forma de mate, cántaro globular con asa." (Cárdenas, 1975: 341).

Como parte de los informes de campo que conserva el Seminario de Arqueología sobre las excavaciones en las Huacas Pando, existe un manuscrito donde se describen los hallazgos en los Entierros 51, 52 y 53 de Huaca La Luz I. Si bien hay un error en la numeración de los contextos, la descripción del Entierro 52 (consignado en el manuscrito como Entierro 51) es abundante (Figura 20):
"El cráneo se halla a 1.80 [metros] de profundidad [y] a los 2,20 mt. finaliza el entierro, el cadáver se halla en posición fetal, y las órbitas de los ojos del cráneo están en dirección S.O. Todo el cadáver se hallaba envuelto en una tela burda muy deteriorada formando un fardo de tipo cónico de aproximadamente $80 \mathrm{~cm}$ en la parte más ensanchada.

El cráneo se hallaba incompleto no notándose la presencia del llamado hueso incaico, las suturas craneanas están visibles, la sutura metópica había desaparecido. En el hueso occipital

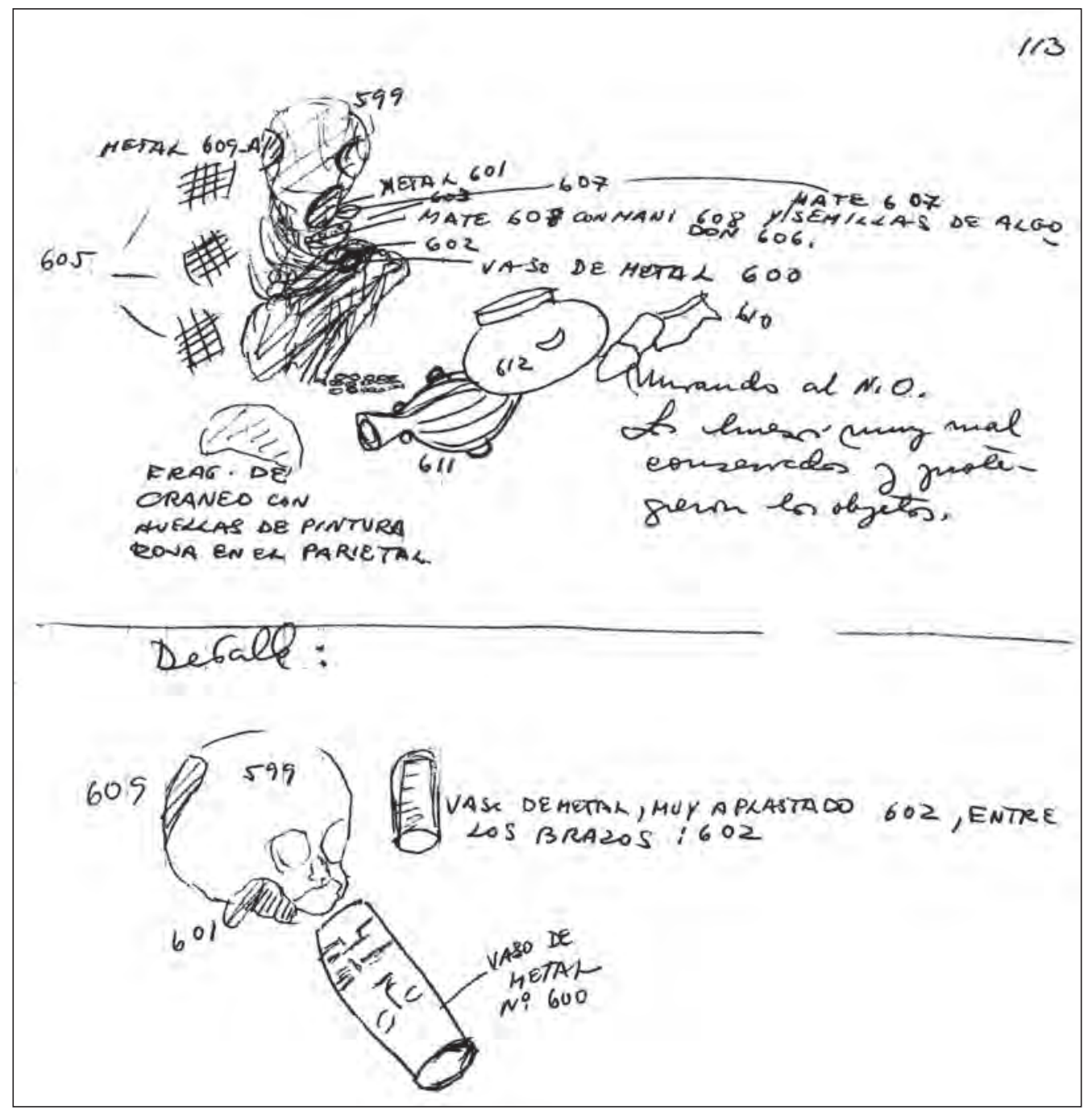

Figura 20. Dibujo del fardo del Entierro 52, erróneamente consignado como Entierro 51. (Seminario de Arqueología del Instituto Riva-Agüero de la Pontificia Universidad Católica del Perú). 
se encontraba pegada una lámina de cobre, de igual manera se hallaron dos láminas de cobre más pequeñas en la parte posterior del hueso occipital. La dentadura se hallaba completa, todos los dientes inclusive los últimos molares habían sido remplazados, los dientes presentaban restos de calcificaciones similares a las que hoy día se pueden apreciar en los dientes de los 'chacchadores' de coca. El esqueleto parece ser de un hombre adulto.

Especie 600.- vaso de cobre de forma troncocónica, con cabeza humana en relieve, y con base pedestal, se hallaba a la altura del esternón del cadáver colocado en forma transversal a este, el vaso es de cobre bañado en plata y con algunas aplicaciones como los ojos en plata.

Especie 601-a-b- Trozos de metal con aleación de cobre colocados a la altura del cuello del esqueleto.

especie 602- vaso de plata con aleación de cobre en forma de kero de $15 \mathrm{~cm}$ de alto.

especie 603- depilador de metal.

especie 604- restos de metal.

especie 605- trozos de tela que envolvía al cadáver, presenta huellas de color rojo.

especie 603 [606]- semillas de algodón se hallaban colocadas dentro de la especie 602 .

especie 607- restos de lagenaria o mate que se hallaba colocado debajo de la mandíbula del cadáver, contiene semillas de maní (especie 608).

especie 609- a. B- Trozo de cobre fragmentado colocado en el hueso occipital del cadáver." (Alvarado 1968: 2-3).

En esta última descripción, la tela que envolvía al individuo es de color rojo, mientras que en la primera descripción es el individuo el que presenta restos de pintura. Es muy posible que se trate de la misma pintura roja asociada a la tela del fardo, y por tanto de cinabrio, cuyo uso como pigmento funerario se conoce al menos desde el periodo Formativo (Onuki 1997; Vetter et al. 2011).

El individuo del Entierro 52 podría tratarse de un personaje importante de la sociedad ychsma, ya que no solo tiene pintura roja como parte de su preparación sino también varias piezas de metal, entre ellas dos vasos de plata, piezas de uso ritual entre las élites gobernantes.
Los vasos narigones -llamados así porque representan rostros antropomorfos con nariz aguileña- son comunes en todos los valles de la costa central. Baessler (1906) menciona el hallazgo de varios vasos de plata y algunos de oro en los sitios de Márquez y Chuquitanta, ahora destruidos, del valle de Chillón. En el valle de Lurín, estos vasos de plata se han encontrado en Pachacámac como ofrenda de cierre de un sitio arquitectónico (Vetter 2004; Vetter y Villacorta 2001). En el valle del Rímac también se han encontrado estos objetos de plata en la Huaca La Luz I -hallazgo mencionado líneas arriba- y Huaca Conde de Las Torres ubicada a la altura de la cuadra 35 de la avenida Argentina en Lima (Bazán 2008). Por último, también se tienen evidencias de estos vasos en la isla San Lorenzo, donde se encontró un caso asociado a una mujer tejedora (Hudtwalcker 2009).

Los vasos narigones tienen tamaños y decoraciones distintas. En algunos casos son de doble cara y en otros sólo tienen una. En este último caso suelen tener un tocado posterior donde se representan mazorcas de maíz, algún tipo de textil, entre otros. Algunos vasos también presentan tocado frontal con la representación de la cabeza de un felino, o con motivos marinos. Carcedo et al. (2004) han realizado un estudio sobre la iconografía y manufactura de estos vasos de la costa central, diferenciándolos de los vasos de la cultura Chimú con los que eran confundidos frecuentemente.

Estos vasos fueron utilizados para la libación en las ceremonias y ritos, y el material con que se confeccionaban estaba relacionado con la jerarquía del portador, es así que los vasos de oro o plata-denominados aquillas- fueron usados por los gobernantes o sacerdotes que propiciaban las ceremonias de libación (Vetter 2009).

\section{COMENTARIOS FINALES}

El estudio de la orfebrería en la costa prehispánica ha sido desigual. La costa norte es investigada desde hace más de treinta años con énfasis en la metalurgia y en general los procesos relacionados con el trabajo del metal, desde la extracción de los minerales, pasando por su 
transformación en metal, hasta la elaboración misma de la pieza.

La costa central se encuentra en desventaja pues los investigadores están inmersos en la problemática de la seriación cerámica o en el desarrollo arquitectónico, y no muestran interés en un estudio integral de la metalurgia, ubicando yacimientos de minerales, talleres de fundición y de orfebrería.

En este trabajo hemos presentado dos sitios que nos dan algunas luces sobre el uso de piezas de metal. El primer caso que mencionamos fue el de Higueras 1-Sector Suroeste donde se halló una buena cantidad de piezas de metal de uso masculino (instrumentos de pesca) y otras de uso femenino (tupus) en grandes conchales. Es interesante que se encuentren piezas de metal en conchales que, como proponemos, tuvieron un fin ritual. Durante los trabajos del PEA Poliducto TgP-Camisea-Tramo Costa 2003-2004 (Salcedo 2004) se encontró en los conchales adyacentes el mismo tipo de objetos de metal. Es importante que los investigadores presten atención a este tipo de sitio, ya que la información que puede proporcionar es valiosa para el entendimiento de la población que les dio origen.

El otro sitio es Huacas Pando, donde se ha podido identificar la mayoría de formas y técnicas usadas en la costa central para la fabricación de piezas de metal, así como el lugar donde fueron colocados estos objetos dentro de los contextos funerarios -si bien estos eran secundarios-. No se ha podido relacionar tipo de objeto con sexo, ya que en la mayoría de casos los restos óseos estaban en pésimo estado de conservación.

En este trabajo hemos tratado de dar una visión del estado actual de las investigaciones en la costa norte y central, presentando los hallazgos más relevantes de ambas zonas, haciendo hincapié en que la costa central tuvo también un desarrollo metalúrgico, quizás en menor escala que en el norte, pero no por eso menos importante para su investigación. Futuros descubrimientos en la costa central proporcionarán nuevas evidencias de la orfebrería en esta zona.

\section{Agradecimientos}

Deseamos agradecer a Transportadora de Gas del Perú (TgP), Walsh Perú S.A. y Trashumantes S.A.C., particularmente a su gerente general, la licenciada Lucía Balbuena, por permitir el acceso a los materiales e información de las excavaciones del Proyecto de Rescate Arqueológico Loop Costa.

Asimismo, agradecemos a la doctora Margarita Guerra, directora del Instituto Riva-Agüero de la Pontificia Universidad Católica del Perú; al arqueólogo Sergio Barraza, director del Seminario de Arqueología de dicha institución; la doctora Inés del Águila, directora del Museo de Arqueología "Josefina Ramos de Cox" IRA - PUCP; y a la licenciada Milagritos Jiménez, curadora de dicho museo, por facilitar el estudio de parte de sus colecciones.

Finalmente, damos las gracias a Álvaro Acevedo, Paloma Carcedo, Víctor Curay, Glenda Escajadillo, Anne Marie Hocquenghem, Pilar Portocarrero y Luis Felipe Villacorta por sus aportes a este trabajo.

\section{Biblografía}

Aldenderfer, Mark; Nathan Craig; Robert Speakman y Rachel Popelka-Filcoff

2008 "Four-thousand-year-old gold artifacts from the Lake Titicaca basin, southern Peru". Proceedings of the National Academy of Sciences 105 (3): 5002-5005.

Alva, Walter

2004 Sipán, Descubrimiento e investigación. Lima: Cervecería Backus \& Johnston S.A.

2008 "Las Tumbas Reales de Sipán". En Makowski, Krzysztof (ed.) Señores de los Reinos de la Luna. 266-279. Lima: BCP.

Alvarado, Margarita

1968 Informe de las excavaciones en la Huaca de la Urbanización La Luz. Manuscrito. Lima: IRA-PUCP.

Baessler, Arthur

1906 Altperuanische Metallgeräte. Berlín: Verlag von Georg Reimer. 
Bazán, Francisco

2008 "Los contextos funerarios Ichma Inicial de Conde de Las Torres". Arqueología y Sociedad 19: 9-22. Lima: Museo de Arqueología y Antropología, Centro Cultural de San Marcos, Universidad Nacional Mayor de San Marcos.

Bezúr, Aniko

2003 Variability in Sicán copper alloy artifacts: its relation to material flow patterns during the Middle Sicán Period in Peru, aD. 900-1100. A dissertation submitted to the Faculty of the Department of Materials Science and Engineering in partial fulfillment of the requirements for the Degree of Doctor of Philosophy in the Graduate College of The University of Arizona.

Bourget, Steve

2009 Lord of the Ucupe. An elite Moche Tomb at HuacaElPueblo. En < http://www.utexas. edu/courses/arh400/lectures/390/weblec.htm >

Burger, Richard y Robert Gordon

1998 "Early Central Andean Metalworking from Mina Perdida, Peru". Science 282 (5391): 1108-1111.

Carcedo, Paloma

2007 Oro del antiguo Perú. Lima: UNIMUNDO.

2005 "Metalurgistas y orfebres precolombinos: entre lo humano y lo divino del metal". En Catálogo de la exposición: Y llegaron los Incas, 91-103. Madrid: Museo de América.

1998 Técnicas en la orfebrería del oro Sicán. Catálogo para la exposición "Gold of Perú". 197-214. Japón: Fuji Television Group.

Carcedo, Paloma e Izumi Shimada.

1985 Behind the Golden Mask: Sican Gold Artifacts from Batan Grande, Peru. En Jones, J. (Ed.) Art of Pre-Columbian Gold: Jan Mitchell Collection. 60-75. Londres: Weidenfel and Nicholson.

Carcedo, Paloma y Luisa Vetter

2002 "Instrumentos utilizados para la fabricación de piezas de metal para el período inca". 50 Congreso Internacional de Americanistas, Varsovia, Polonia.
Julio, 2000. Baessler Archiv 50: 47-66. Ethnologisches Museum de Berlín, Alemania.

Carcedo, Paloma, Luisa Vetter y Magdalena Diez Canseco

2004 "Los vasos efigie antropomorfos: un ejemplo de la orfebrería de la costa central durante el Intermedio Tardío-Horizonte Tardío". Boletín de Arqueología PUCP 8: 151-189. Lima.

Cárdenas, Mercedes

1975 Informes preliminares de los trabajos arqueológicos realizados en los años 1969. 1974, autorizados por la Resolución Suprema No. 1074 de fecha 19 de noviembre de 1969. I y II tomos. Manuscrito. Lima: Seminario de Arqueología del Instituto Riva Agüero de la Pontificia Universidad Católica del Perú.

Castillo, Luis Enrique

2009 Tratamiento de conservación y restauración de vasos de plata de la cultura Chimú. Ponencia presentada en el II Congreso Latinoamericano de Arqueometría, 19-21 de octubre, Lima.

Castillo, Luis Jaime

2000 "The evolution of complex societies in ancient Peru". En Rain of the Moon. Silver in Ancient Peru. 16-23. The Metropolitan Museum of Art. Yale University Press.

Curay, Víctor

2003 Producción de objetos de cobre en el valle de Lambayeque: El Complejo S165 de Pampa de Burros. Ponencia presentada en el VI Seminario de Investigaciones Sociales en la Región Norte, desarrollado en la Universidad Nacional Pedro Ruiz Gallo, Lambayeque, el 3 de octubre de 2003.

Dolorier, Camilo y Lyda Casas

2008 "Caracterización de algunos estilos locales de la Costa Central a inicios del Intermedio Tardío". Arqueología y Sociedad 19: 23-42. Lima: Museo de Arqueología y Antropología, Centro Cultural de San Marcos, Universidad Nacional Mayor de San Marcos. 
Donnan, Christopher

2007 Moche Tombs at Dos Cabezas. California: Cotsen Institute of Archaeology at UCLA. Monograph 59.

Eeckhout, Peter

2004a "La sombra de Ychsma. Ensayo introductoria sobre la arqueología de la costa central del Perú en los periodos Tardíos". En Eeckhout, Peter (Ed.) Arqueología de la costa central del Perú en los periodos tardios. Bulletin de l'Institut Français d'Études Andines 33(3): 403423, Lima.

2004b "Pachacamac y el proyecto Ychsma (1999-2003)". En Eeckhout, Peter (Ed.) Arqueología de la costa central del Perú en los periodos tardíos. Bulletin de l'Institut Français d'Études Andines 33(3): 425. 448, Lima.

2000 "Investigaciones arqueológicas en la pirámide No. III de Pachacamac, costa central de Perú". Estudios Latinoamericanos 20: 19-40, Varsovia.

El Comercio

2011 "Descubren joyas de oro en tumba de importante personaje lambayeque". Sección A14, jueves 10 de setiembre.

Elera, Carlos

2008 "Sicán: Arquitectura, tumbas y paisaje". En Makowski, Krzysztof (Ed.) Señores de los Reinos de la Luna. 304-313. Lima: Banco de Crédito del Perú.

Elera, Carlos y José Pinilla

1990 "Research summary of the Proyecto Arqueológico Puémape (1987-1989)". Willay 34: 2-4, Cambridge, Massachussetts.

Falconí, Iván

2008 "Caracterización de la cerámica de la fase Ychsma Meido del sitio de Armatambo, Costa Central de Perú”. Arqueología y Sociedad 19: 43-66. Lima: Museo de Arqueología y Antropología, Centro Cultural de San Marcos, Universidad Nacional Mayor de San Marcos.

Feltham, Jane y Peter Eeckhout

2004 "Hacia una definición del estilo Ychsma: aportes preliminares sobre la cerámica Ychsma tardía de la pirámide III de
Pachacamac". En Eeckhout, Peter (Ed.) Arqueología de la costa central del Perú en los periodos tardios. Bulletin de l'Institut Français d'Études Andines 33(3): 643 680. Lima.

Franco Jordán, Régulo

2008 "La señora de Cao". En Makowski, Krzysztof (Ed.) Señores de los Reinos de la Luna. 280-287. Lima: Banco de Crédito del Perú.

2004 "Poder religioso, crisis y prosperidad en Pachacamac: del Horizonte Medio al Intermedio Tardío". En Eeckhout, Peter (Ed.) Arqueología de la costa central del Perú en los periodos tardíos. Bulletin de l'Institut Français d'Études Andines 33(3): 465-506. Lima.

Griffin, Jo Ann e Izumi Shimada

1994 "Goldworking in prehispanic Americas". En Ono, Masahiro (Ed.) Sicán: Excavations at the Pre-Inca Golden Capital - Catalogue. 122-131. Tokio: Tokio Broadcasting System.

Guerrero, Daniel

2004 "Cronología cerámica y patrones funerarios del valle del Rímac: una aproximación a los periodos tardíos". En Villacorta, L. F; L. Vetter y C. Ausejo (Eds.) Puruchuco y la sociedad de Lima: un homenaje a Arturo Jiménez Borja. 157167. Lima: CONCYTEC y Compañía de Minas Buenaventura S.A.

Hocquenghem, Anne Marie

2010 "El Spondylus princeps y la Edad de Bronce en los Andes Centrales: Las rutas de intercambios". En Melgar, E.; R. Solís y E. González (Comp.) Producción de bienes de prestigio ornamentales y votivos de la América antigua. 34-49. Florida: Publicación electrónica de Syllaba Press 7, Serie Arqueología Mesoamericana. <http:// www.syllabapress.com/temp $>$.

2004 "Una edad del bronce en los Andes Centrales: Contribución a la elaboración de una historia ambiental". Bulletin de l'Institut Français d'Études Andines 33 (2): 271-329. Lima. 
Hocquenghem, Anne Marie y Luisa Vetter

2005 "Las puntas y rejas prehispánicas de metal en los Andes y su continuidad hasta el presente". Bulletin de l'Institut Français d'Etudes Andines 34 (2): 141-159. Lima.

Hudtwalcker, José Antonio

2009 "La tejedora de San Lorenzo: historia de un desenfardelamiento". En < http:// www.islasdelperu.com >

Mayer, Eugen

1998 Armas y herramientas de metal prehispánicas en Perú. Verlag Philipp von Zabern - Mainz am Rhein.

Morales, Ricardo

2004 "Atuendo ritual moche en Huaca de la Luna: apuntes para una interpretación iconográfica en contexto". En Uceda, S.; E. Mujica y R. Morales editores Investigaciones en la Huaca de la Luna 1998-1999. 377-387. Proyecto Arqueológico Huacas Sol y de la Luna. Facultad de Ciencias Sociales, Universidad Nacional de Trujillo.

Mujica, Elías

2007 El Brujo. Huaca Cao. Centro Ceremonial Moche en el Valle de Chicama. Fundación Wiese, Lima.

Onuki, Yoshio

1997 "Ocho tumbas especiales de Kuntur Wasi". Boletín de Arqueología PUCP 1: 79- 114. Lima.

Onuki, Yoshio y Kinya Inokuchi

2011 Gemelos Prístinos. El tesoro del Templo de Kuntur Wasi. Lima: Fondo Editorial del Congreso del Perú. Minera Yanacocha.

Ramos de Cox, Josefina

1970 "Excavaciones de unidades arqueológicas en el Fundo Pando-Lima". Boletín del Seminario de Arqueología 7: 78-81. Lima: Instituto Riva Agüero-Pontificia Universidad Católica del Perú.

Reiss, Wilhelm y Alphons Stübel

1998 [1880-1887] The Necropolis of Ancon in Peru. A contribution to our knowledge of the culture and industries of the Empire of the Incas. Hannover.
Ríos, Marcela y Enrique Retamozo

1978 "Objetos de metal procedentes de la Isla de San Lorenzo". Arqueológicas 17. Lima.

1982 Vasos ceremoniales de Chan Chan. Lima.

Rostworoswki, María

1978 Señoríos indígenas de Lima y Canta. Lima: Instituto de Estudios Peruanos.

Salcedo, Luis Enrique

2004 PEA Poliducto TGP Camisea - Tramo Costa. Informe presentado al INC en Diciembre de 2004. Lima. Manuscrito.

Seki, Yuji

1997 "Excavaciones en el sitio La Bomba, Valle Medio de Jequetepeque, Cajamarca". Boletín de Arqueología PUCP 1: 114. 136. Lima.

Shimada, Izumi

1994 Pampa Grande and the Mochica Culture. Austin: University of Texas Press.

1995 Cultura Sicán. Dios, riqueza y poder en la costa norte del Perú. Lima: Fundación del Banco Continental para el Fomento de la Educación y la Cultura, Edubanco.

Shimada, Izumi (editor)

1991 [1903] Pachacamac. A Reprint of the 1903 Edition by Max Uhle, University Museum Monograph 62. Filadelfia: Department of Archaeology and Anthropology, University of Pennsylvania.

Shimada, Izumi y Jo Ann Griffin

1994 "Precious metal objects of the Middle Sicán". Scientific American, Abril: 6067.

Shimada, Izumi; Jo Ann Griffin y Adon Gordus

2000 "The Technology, Iconography and Social Significance of Metals: A MultiDimensional Analysis of Middle Sican Objects". En McEwan, Colin (Ed.) PreColumbian Gold: Technology, Style and Iconography. 28-61. Londres: The Bristish Museum Press.

Squier, George E.

1974 [1877] Un viaje por tierras incaicas. Crónica de una expedición arqueológica (18631865). Lima: Edición en español auspiciada por la Universidad Nacional Mayor de San Marcos y la Embajada de los Estados Unidos. 
Topic, John

1990 "Craft Production in the Kingdom of Chimor". En Moseley, Michael E. y Alana Cordy-Collins (Eds.) The Northern Dynasties: Kingship and Statecraft in Chimor. 145-176. Washington D.C.: Dumbarton Oaks Research Library and Collection.

Transportadora de Gas del Perú (TgP)

2009 Informe de término de rescate arqueológico del sitio Higueras 1-Sector Suroeste. Informe preliminar presentado al INC. Lima. Manuscrito.

Vallejo, Francisco

2008 "Desarrollo y complejización de las sociedades tardías de la Costa Central: El caso de Ychsma”. Arqueología y Sociedad 19: 83-115. Lima: Museo de Arqueología y Antropología, Centro Cultural de San Marcos, Universidad Nacional Mayor de San Marcos.

Vetter, Luisa

1993 Análisis de las puntas de aleación de cobre de la tumba de un señor de la elite sicán, Batán Grande, Lambayeque, Perú. Tesis para optar el grado de Bachiller. Pontificia Universidad Católica del Perú. Lima.

1996 "El uso del cobre arsenical en las culturas prehispánicas del norte del Perú”. 49 Congreso Internacional de Americanistas, Quito, 1997. Boletín Museo del Oro 41:63-81. Bogotá.

2004 "Las piezas de metal del Museo de Sitio Arturo Jiménez Borja-Puruchuco". En Villacorta, L. F.; L. Vetter y C. Ausejo (Eds.) Puruchuco y la Sociedad de Lima: un homenaje a Arturo Jiménez Borja. 119. 139. Lima: CONCYTEC y Compañía de Minas Buenaventura S.A.

2006 Oro del Perú antiguo. Roberto Gheller editor. Lima.

2009 "Bevande, musica e libagioni nei riti preispanici: il bicchiere come elementoguida". En Inca: Origine e misteri delle civiltá dell'oro. 140-163. Brescia.
Vetter, Luisa y Paloma Carcedo

2009 El Tupo: Símbolo ancestral de identidad femenina. Lima.

Vetter, Luisa, Susana Petrick y Paula Olivera

2011 "Estudio arqueométrico de piezas de oro de Morro de Éten, Perú”. En Vetter, L.; R. Vega-Centeno; P. Olivera y S. Petrick (Eds.) II Congreso Latinoamericano de Arqueometría. Lima, 19 al 21 Octubre de 2009. 73-86. Lima: Fondo Universidad Nacional de Ingeniería, Organización de Estados Iberoamericanos e Instituto Peruano de Energía Nuclear.

Vetter, Luisa y Luis Felipe Villacorta

2001 "La Arqueometalurgia de la costa central del Perú: Una perspectiva desde la colección del Museo de Sitio Arturo Jiménez Borja - Puruchuco". Baessler Archiv 49: 193-210. Berlín: Ethnologisches Museum de Berlín.

Vetter, Luisa, Paloma Carcedo, Sócrates Cutipa y Eduardo Montoya

1997 "Estudio descriptivo, metalográfico y químico de las puntas de aleación de cobre de la tumba de un Señor de la élite Sicán, Lambayeque, Perú, empleando técnicas de microscopía óptica y análisis por activación neutrónica". Revista Española de Antropología Americana 27: 23-38. Madrid: Servicio Publicaciones UCM.

Villacorta, Luis Felipe

2004 "Los palacios en la costa central durante los periodos tardíos: de Pachacamac al Inca". En Eeckhout, Peter (Ed.) Arqueología de la costa central del Perú en los periodos tardios. Bulletin de l'Institut Français d'Études Andines 33(3): 538-570. Lima.

Wiener, Charles

1993 [1880] Pérou et Bolivia. Récit de Voyage. Paris. Edición traducida al español. Lima: IFEA, UNMSM. 